Florida International University FIU Digital Commons

$10-29-2014$

\title{
Household Preferences for Financing Hurricane Risk Mitigation: A Survey Based Empirical Analysis
}

Damon Fitzgerald

dfitz001@fiu.edu

DOI: $10.25148 /$ etd.FI14110759

Follow this and additional works at: https://digitalcommons.fiu.edu/etd

Part of the Applied Statistics Commons, and the Social Statistics Commons

\section{Recommended Citation}

Fitzgerald, Damon, "Household Preferences for Financing Hurricane Risk Mitigation: A Survey Based Empirical Analysis" (2014). FIU Electronic Theses and Dissertations. 1725.

https://digitalcommons.fiu.edu/etd/1725 


\title{
FLORIDA INTERNATIONAL UNIVERSITY \\ Miami, Florida
}

\section{HOUSEHOLD PREFERENCES FOR FINANCING HURRICANE RISK MITIGATION: A SURVEY BASED EMPIRICAL ANALYSIS}

\author{
A thesis submitted in partial fulfillment of the \\ requirements for the degree of \\ MASTER OF SCIENCE \\ in \\ STATISTICS \\ by
}

Damon N. Fitzgerald 


\section{To: Interim Dean Michael R. Heithaus}

College of Arts and Sciences

This thesis, written by Damon N. Fitzgerald, and entitled Household Preferences for Financing Hurricane Risk Mitigation: A Survey Based Empirical Analysis, having been approved in respect to style and intellectual content, is referred to you for judgment.

We have read this thesis and recommend that it be approved.

$\begin{array}{r}\hline \text { Sneh Gulati } \\ \hline \text { Pallab Mozumder, Co-Major Professor } \\ \hline \text { B.M. Golam Kibria, Co-Major Professor }\end{array}$

Date of Defense: October 29, 2014

The thesis of Damon N. Fitzgerald is approved.

\begin{tabular}{r}
\hline $\begin{array}{r}\text { Interim Dean Michael R. Heithaus } \\
\text { College of Arts and Sciences }\end{array}$ \\
\hline Dean Maureen A Donnelly \\
University Graduate School
\end{tabular}

Florida International University, 2014 
C Copyright 2014 by Damon N. Fitzgerald All rights reserved. 


\section{DEDICATION}

I dedicate this thesis to my wife, Lora. None of this would have been possible without your love and support. 


\section{ACKNOWLEDGMENTS}

I would like to express my deepest gratitude to my committee members, friends, and my family and wife for helping me throughout this thesis project. Each of you has been an important part of my ability to complete this master's thesis.

I would like to thank my thesis advisor, Dr. B.M. Golam Kibria, for your guidance and continued support through out this project. Your enthusiasm, patience, highly instructive coursework and extensive knowledge have been invaluable part of my completion of this thesis.

Besides my advisor, I would like to thank the rest of my thesis committee: Dr. Pallab Mozumder and Dr. Sneh Gulati for their insight, encouragement, and always informative comments. Thank you to Dr.Mozumder for the opportunity to work with you during my summer internship at the International Hurricane Research Center. As my co-major committee member you have brought a crucial aspect of research experience and knowledge, from the field of economics, to my final thesis. My thanks to Dr.Gulati for her always insightful comments and questions throughout this project. I have no doubt that my term projects in your Data Analysis courses were an indispensable experience for my development and completion of this thesis endeavor.

Finally I would like to thank my wife, Lora Namoff. Your unwavering support of me throughout this project and during my graduate school career has enabled me to complete a lifelong dream. 


\title{
ABSTRACT OF THE DISSERTATION \\ HOUSEHOLD PREFERENCES FOR FINANCING HURRICANE RISK \\ MITIGATION: A SURVEY BASED EMPIRICAL ANALYSIS
}

by

\author{
Damon N. Fitzgerald \\ Florida International University, 2014 \\ Miami, Florida \\ Professor B.M. Golam Kibria, Co-Major Professor \\ Professor Pallab Mozumder, Co-Major Professor
}

After a series of major storms over the last 20 years, the state of financing for U.S. natural disaster insurance has undergone substantial disruptions causing many federal and state backed programs against residential property damage to become severally underfunded. In order to regain actuarial soundness, policy makers have proposed a shift to a system that reflects risk-based pricing for property insurance. We examine survey responses from 1394 single-family homeowners in the state of Florida for support of several natural disaster mitigation policy reforms. Utilizing a partial proportional odds model we test for effects of location, risk perception, socio-economic and housing characteristics on support for policy reforms. Our findings suggest residents across the state, not just risk-prone homeowners, support the current subsidized model. We also examine several other policy questions from the survey to verify our initial results. Finally, the implications of our findings are discussed to provide inputs to policymakers. 


\section{TABLE OF CONTENTS}

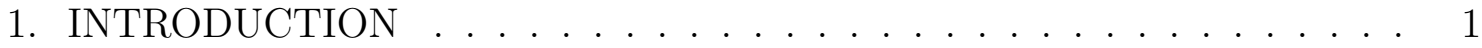

2. ANALYTICAL FRAMEWORK AND EMPIRICAL SPECIFICATION . . 6

Stochastic Utility Model . . . . . . . . . . . . . . . . . . . . . 6

Model Specification . . . . . . . . . . . . . . . . . . . . . . . . . 10

3. SOURCES OF DATA . . . . . . . . . . . . . . . . 15

Survey . . . . . . . . . . . . . . . . . . . . . . . . . . 15

Sample Characteristics . . . . . . . . . . . . . . . . . . . 15

Measures . . . . . . . . . . . . . . . . . . . . . 16

4. DATA ANALYSIS AND RESULTS . . . . . . . . . . . . . . 23

Data Analysis . . . . . . . . . . . . . . . . . . . . . . . . 23

Model Fitting . . . . . . . . . . . . . . . . . . . . . 26

Results . . . . . . . . . . . . . . . . . . . 30

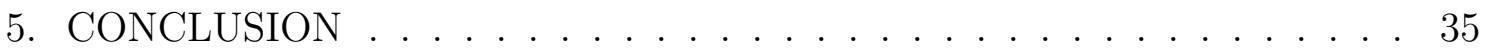

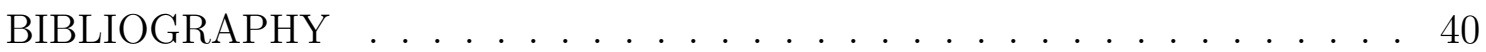

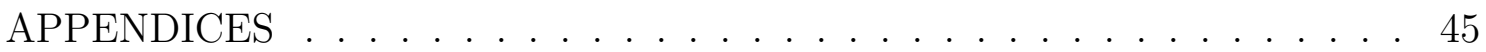




\section{CHAPTER 1 \\ INTRODUCTION}

Following an extended period of natural disasters in various U.S. coastal regions, the insurance market for residential properties has undergone significant financial instability (Kunreuther and Michel-Kerjan, 2009). Public mechanisms for natural disaster reinsurance have seen dramatic shortfalls following the major storm activity over the last ten years. After a high number of coastal storms in 2005, the Federal Emergency Management Agency (FEMA) was forced to borrow $\$ 17$ billion from the U.S. treasury after its actuarial soundness came into question (Petrolia et al., 2011). Following major storms Katrina, Irene, Isaac and Sandy the National Flood Insurance Program (NFIP) was pushed into near bankruptcy by approximately $\$ 24$ billion in debt (Davenport, 2014). Various state reinsurance programs have had to grapple with financial shortfalls as well. Florida's legislature passed a one percent insurance surcharge on all policy types in order to cover a $\$ 625$ million loss to its Hurricane Catastrophe Fund following the 2005 hurricane season(Kern, 2008).

Following the near bankruptcy of the NFIP in 2012, congress enacted the BiggertWaters Act $^{1}$ which required "...the NFIP to raise rates to reflect true flood risk,

\footnotetext{
${ }^{1}$ Biggert-Waters Flood Insurance Reform Act of 2012 was a series of reforms to the FEMA administered National Flood Insurance Program (NFIP) executing by Congress to address the NFIP's financial sustainability. The legislation was designed to, in the words of then current administrator of FEMA Craig Fugate, "Significant concentrated losses in high policy coverage areas [which] could set the program up for future losses beyond the authorized borrowing authority." The main focus of Biggert-Waters was to remove most of the subsidies and grandfather rates from NFIP which FEMA had deemed as the main cause of the program's financial instability after the significant damage of Hurricanes Katrina (2005) and Sandy (2012). Starting in January 1, 2013 property owners with subsidized policyholders saw a $25 \%$ increase. Rate increases would continue for these policy holders would continue "...until rates reflect true risk" (FEMA, 2014). Please see http://www.fema.gov/media-library-data/1395864920638-
} 
Table 1.1: Top 10 costliest Atlantic hurricanes, inflation adjusted 2014 Billions USD.

\begin{tabular}{|rrrrr|}
\hline Name & Damage & Season & Peak intensity & Areas affected \\
\hline Katrina & 152 & 2005 & Cat 5 & The Bahamas, U.S. Gulf Coast \\
Sandy & 73.9 & 2012 & Cat 3 & The Caribbean, U.S. East Coast \\
Andrew & 44.9 & 1992 & Cat 5 & The Bahamas, Florida, U.S. Gulf Coast \\
Ike & 41.4 & 2008 & Cat 4 & Greater Antilles, Texas, Louisiana, Midwestern U.S. \\
Wilma & 35.6 & 2005 & Cat 5 & Greater Antilles, Central America, Florida \\
Ivan & 29.3 & 2004 & Cat 5 & The Caribbean, Venezuela, U.S. Gulf Coast \\
Charley & 19 & 2004 & Cat 4 & Jamaica, Cayman Islands, Cuba, Florida, The Carolina s \\
Irene & 17.5 & 2011 & Cat 3 & The Caribbean, U.S. East Coast, Eastern Canada \\
Rita & 14.6 & 2005 & Cat 5 & Cuba, U.S. Gulf Coast \\
Frances & 12.4 & 2004 & Cat 4 & The Caribbean, Eastern U.S., Ontario \\
\hline
\end{tabular}

Source: NOAA Technical Memorandum NWS TPC-5

make the program more financially stable, and change how Flood Insurance Rate Map (FIRM) updates impact policyholders."(FEMA, 2014) These policy increases may entice private insurers back into the market and allow for a greater externalization of natural disaster risks (Hornstein, 2013). This has been meet with issues of affordability from policy holders in flood-prone homes, which will see a significant increase in their rates with a removal of subsidies (Davenport, 2014). After passage of Biggert-Waters, a significant backlash among policy holders in coastal regions emerged. This lead to many of the law's strongest provisions related to correct pricing of current subsidized policies to be be repealed or delayed, which has again raised concerns over the financial solvency of NFIP (Verchick and Johnson, 2014).

Increased development into hazard prone U.S. coastal areas has only exacerbated problems in Federal and State natural disaster insurance programs (Bagstad et al., 2007). A mixture of poor planning by local officials and popular Federal and State subsidies have incentivized continued development into higher risk areas. Moves towards creating more sustainable programs which more accurately reflect

184532a45a49062ffa8eccdc0f863db1/11-19-2013_IMPLEMENTATION $\backslash \% 200 \mathrm{~F} \backslash \% 20 \mathrm{THE} \backslash$ $\% 20 B I G G E R T$-WATERS $\ \% 20 F L O O D \backslash \% 20$ INSURANCE $\backslash \% 20 R E F O R M \backslash \% 20 A C T \backslash \% 200 F \backslash \% 202012$. pdf for further information. 
property risk are met with negative reaction by a variety of interest groups (i.e., Homeowners, real estate developers, and the construction industry). Residents lack of risk information due to heavily subsidized premiums continues to create economic inefficiencies which could lead to tragic consequences.

New directions in policy have included innovative programs that incentivize homeowners mitigation status, with emphasis on helping low-income households in high risk areas (Chatterjee and Mozumder, 2014). Kunreuther and Michel-Kerjan (2009) outlines several proposals for dealing with catastrophic risk including extending terms on required flood insurance coverage for homeowners residing in flood zones. The creation of a National All-hazards Insurance contract could diversify a multitude of risks including storm damage (flood, and wind storm), and decrease the likelihood of losses for the insurer. While a diversity of policy ideas have emerged recently, the public's perception of the benefits and costs associated with these programs are key to their passage and implementation. Therefore, it is paramount that policy makers have an understanding of homeowners preferences for these types of policy reforms in order to effectively mobilize their constituency.

\section{Background}

The state of Florida is a natural place of study for natural disaster mitigation, specifically hurricane risk (Kunreuther and Michel-Kerjan, 2009). A microcosm of potential conflict for policy reform, the state has been "...widely considered the epicenter of the debate with respect to hurricane risk financing" (Cole et al., 2011; Grace and Klein, 2009). Florida currently makes up approximately 37\% of all National Flood Insurance Policies (NFIP), which represents the largest share in force by the federally backed program (FEMA, 2014). Of the policies in force for the 
state, nearly $80 \%$ are for single family homes. Kunreuther (2009), in examining Florida's flood insurance market found that nearly $75 \%$ of single family home polices lie within the FEMA-designated hundred-year floodplains. Despite the potential exposure these homeowners face, Michel-Kerjan and Kousky (2010) found the average premium per policy in Florida is among the lowest in the nation. With the passage of the Biggert-Waters act nearly $13 \%$ of NFIP policy holders in the state could see an increase in their rates (Harrington, 2013). The state's property loss reinsurer, the Florida Hurricane Catastrophe Fund (FHCF), and it's property insurance arm, Citizens Property Insurance Corporation, have come under criticism for their current financing structure. Surcharge assessments from storm damage, which disproportionately represent coastal property owners, are covered by all residents insured within the state. Cole et al. (2011) studied the subsidy payout per county and found an unequal distribution among counties. In it's current fiduciary relationship with the state all losses for FHCF and Citizens are covered by across the board insurance rate increases (property, auto, etc.) in the form of surcharges for all residents of Florida.

An understanding of the Florida public's perception of hurricane mitigation financing reform is critical to effective implementation and adoption of new policies. Uncertainty regarding benefits associated with policy reforms can lead individuals to default to the knowable choice à la the status quo (Fernandez and Rodrik, 1991). Significant theoretical and empirical research on the "status quo" effect has been developed through out the preference theory literature (Bagstad et al., 2007; Paetzel et al., 2012) in particular as relates to public policy support. A citizens lack of knowledge of specific policy reforms can lead to preferences based on underlying hurricane risk perception and the potential benefits to mitigation behaviors. Peacock et al. (2005) examined survey results from the state of Florida to find mean 
perceived hurricane risk by location in wind zone as significant. The studies results suggest that Florida residents' perception of risk is proportional to the level of risk associated with their geographical location (i.e., flood zone, distance from the coast, etc.). However adoption of hurricane risk mitigation activities has not been found to be as consistent. In examining Florida residence allowance of a free household hurricane mitigation inspection by the state as a proxy of demand for hurricane risk information, Chatterjee and Mozumder (2014) found certain high risk households (manufactured/mobile home owners) less likely to allow inspection. On the national level, Leiserowitz (2006) examined American's perception of risk from climate change in association with support for raising various taxes. While perception of the risks from climate change were found to be high, support for raising business and gasoline taxes was low. Results from the study were examined using the Collective Interest (CI) framework which posits that individuals will participate in "...a collective endeavor when the expected value of participation is greater than not participating." (Leiserowitz, 2006)

The following is an analysis of natural disaster risk financing reform by examining the factors that explain Florida resident's variance in support. The remainder of this research is organized as follows. In chapter 2 we first develop the theoretical and empirical specification to understand households preference for policy reform. Next in chapter 3, using results from a recent survey of Florida homeowners, we define the variables used in this study. This is followed by chapter 4 with a detailed analysis and modeling of policy preferences. Finally chapter 5 discusses results and potential policy implementation. 
CHAPTER 2

\section{ANALYTICAL FRAMEWORK AND EMPIRICAL SPECIFICATION}

\section{Stochastic Utility Model}

We develop the analytic framework for understanding the public's support for reform measures by use of the modeling of ordered choices. The concept of preference theory for an ordered scale is often referred to in the literature by a variety of names such as the stochastic utility model, choice modeling, or popular choice models. The development in the social sciences is largely grounded in revealed preference theory, where an individual decision maker must select a single choice (often referred to as a bundle in the economic field) from a set of $k \geq 2$ options (Chapman and Staelin, 1982). In the context of natural disaster mitigation reform in particular we utilize concepts from the efficiency-enhancing reforms literature (Paetzel et al., 2012). Here emphasis is on the individual's ability to distinguish between the optimally efficient choice, a set of sub-optimal choices and the status quo. We develop our model under the assumption that mitigation reform represents an overall positive net benefit for citizens in the state of Florida. Within this context, a Florida citizen must be able to evaluate and identify the benefits and costs associated with the selection of the efficiency enhancing reforms.

To understand the complex relationship of public policy preference of Florida single family homeowners, we implement the ordinal regression model (ORM) in order to analyze survey responses for a measured outcome on a Likert-type scale. The use of ORM is very common in the statistical literature and it's current form was developed by McKelvey and Zavoina (1975) and the widely cited McCullagh (1980). Several comprehensive resources have been published on the subject of 
ORM (Agresti, 2010; Greene and Hensher, 2010; Long, 1997; McCullagh, 1980) in particular Greene and Hensher (2010) give a concise literature review and include an historical overview of the model's development. Their primer identifies over 30 different applications of ORM in the literature include statistical analysis of skill level, education attainment, occupational level and Likert type responses. In particular for this study, the ORM is widely used in the hurricane mitigation literature. Petrolia et al. (2011) employ survey data and experiment-based risk preferences from households in three states, including Florida, to model probabilities for holding flood insurance. A probit specification is used to model a mixture of covariates including risk perception, demographics, and residential structural type. Modeling households decisions for mitigation is measured via shutter usage and envelope coverage by Peacock (2003). Here the dependent variable for the ORM was six ranked categories for window coverage. Mozumder et al. (2011) analyze survey responses from decision makers and experts employed in the Florida Keys on their concern over potential impacts of climate change on the region. A series of ordered logistic regression models are fit to groupings of variables including demographics, climate change concern, and economic loss (via property, natural resources, and tourism revenues). Their findings measure a subset of Florida policymakers implicit understanding of risk and response measures. Stoutenborough et al. (2013) examine competing theoretical interpretations for policy preferences on support for U.S. nuclear energy policies. Covariates used in the model include various attitudinal indicators (trust in government,environmental concerns), knowledge and risk perceptions related to nuclear energy and demographic indicators. We adopt the ordered choice model to examine an individual's rank of preferences for policy change based on their vector of characteristics $x_{i}$. 
Let the response $Y_{i}$ have $j=1,2, \ldots, J$ ordered categories with probabilities $\pi_{1}(\mathbf{x})$, $\pi_{2}(\mathbf{x}), \ldots, \pi_{J}(\mathbf{x})$, and be distributed as multinomial with parameters $(\pi, \mathrm{n})$. Here $\mathbf{x}$ is our vector of covariates for subject $i$, were we define the cumulative probabilities for the probability that the $i^{\text {th }}$ observation falls in or below response category $\mathrm{j}$ as:

$$
\gamma_{j}(\mathbf{x})=P\left(Y \leq j \mid \mathbf{x}_{i}\right)=\pi_{i 1}+\pi_{i 2}+\ldots+\pi_{i j}
$$

In order to capture the notion of stochastic ordering we must adopt a functional form which allows for a monotone increasing mapping of the interval $(0,1)$ onto $(-\infty, \infty)$. We define our general form as:

$$
\operatorname{link}\left(\gamma_{i j}\right)=\alpha_{j}-\boldsymbol{\beta}^{\prime} \mathbf{x}_{\mathbf{i}}
$$

where $\boldsymbol{\beta}$ is the corresponding set of regression parameters for $\mathbf{X}$. Here we develop the model in its general form and leave discussion of the link function to later.

\section{Estimation}

Once a link function is specified, parameter $\left(\alpha_{j}, \boldsymbol{\beta}\right)$ must be computed via Maximum Likelihood Estimation(MLE) methods. Our likelihood function is as follows ${ }^{1}$, let the probability of the observed y belonging to the $j^{\text {th }}$ category for the $i^{\text {th }}$ subject be:

\footnotetext{
${ }^{1}$ The following is adapted from (Agresti, 2010; Christensen, 2011; Greene and Hensher, 2010; Long, 1997).
} 


$$
P\left(y_{i}=j \mid \mathbf{x}_{i}, \boldsymbol{\beta}, \boldsymbol{\alpha}\right)= \begin{cases}F\left(\alpha_{j}-\boldsymbol{\beta}^{\prime} \mathbf{x}_{\mathbf{i}}\right) & \mathrm{j}=1 \\ F\left(\alpha_{j}-\boldsymbol{\beta}^{\prime} \mathbf{x}_{\mathbf{i}}\right)-F\left(\alpha_{j-1}-\boldsymbol{\beta}^{\prime} \mathbf{x}_{\mathbf{i}}\right) & 1<\mathrm{j} \leq \mathrm{J}-1 \\ 1-F\left(\alpha_{J}-\boldsymbol{\beta}^{\prime} \mathbf{x}_{\mathbf{i}}\right) & \mathrm{j}=\mathrm{J}\end{cases}
$$

Here $F$ is the inverse of our prespecified link function. Then our likelihood equation is

$$
\begin{array}{r}
L(\alpha, \beta \mid y, x)=\prod_{i=1}^{N} p_{i}=\prod_{i=1}^{N} \prod_{j=1}^{J} P\left(y_{i}=j \mid \mathbf{x}_{i}, \boldsymbol{\beta}, \boldsymbol{\alpha}\right) \\
=\prod_{i=1}^{N} \prod_{j=1}^{J}\left[F\left(\alpha_{j}-\boldsymbol{\beta}^{\prime} \mathbf{x}_{\mathbf{i}}\right)-F\left(\alpha_{j-1}-\boldsymbol{\beta}^{\prime} \mathbf{x}_{\mathbf{i}}\right)\right]
\end{array}
$$

Taking log of both sides, our log likelihood is

$$
\begin{array}{r}
\log L=\sum_{i=1}^{N} \sum_{j=1}^{J} \log \left[F\left(\alpha_{j}-\boldsymbol{\beta}^{\prime} \mathbf{x}_{\mathbf{i}}\right)-F\left(\alpha_{j-1}-\boldsymbol{\beta}^{\prime} \mathbf{x}_{\mathbf{i}}\right)\right] \\
=\sum_{i=1}^{N} \sum_{j=1}^{J} \log \left(F_{i, j}-F_{i, j-1}\right)
\end{array}
$$

For maximizing our likelihood we take partial derivatives with respect to our parameters $\alpha, \beta$.

$$
\begin{array}{r}
\frac{\partial \log \left(F_{i, j}-F_{i, j-1}\right)}{\partial \beta}=\frac{f_{i, j}-f_{i, j}}{\left(F_{i, j}-F_{i, j-1}\right)}\left(-\mathbf{x}_{\mathbf{i}}\right), \\
\frac{\partial \log \left(F_{i, j}-F_{i, j-1}\right)}{\partial \alpha_{j}}=\frac{f_{i, j}}{\left(F_{i, j}-F_{i, j-1}\right)}, \\
\frac{\partial \log \left(F_{i, j}-F_{i, j-1}\right)}{\partial \alpha_{j-1}}=\frac{f_{i, j-1}}{\left(F_{i, j}-F_{i, j-1}\right)}
\end{array}
$$

Following from standard likelihood theory we next calculate the variance-covariance matrix by way of the Fisher Information matrix $(I(\hat{\theta}))$, here we use the relationship: 
$I(\hat{\theta})=-\mathrm{H}$. Where $\hat{\theta}=[\alpha, \beta]$ and $\mathrm{H}$ is the Hessian matrix of second order derivatives of the log-likelihood function evaluated at the ML estimates. As Christensen (2011) has noted, the covariance variance matrix calculation at this point uses either the expected Fisher information, based on re-weighted least squares methods, or the observed Fisher information, calculated based on Newton-Raphson algorithms. In reality the choice of observed versus expected is a matter of which software is used for the estimates. Once a distributional form has been selected the maximization of the log-likelihood function is carried out by numerical algorithms (typically NewtonRaphson), as no-closed form solution is possible. Further, in order to correctly estimate the model either $\alpha_{1}$ or $\beta_{0}$ is constrained to zero (this is usually software dependent but does not effect the coefficient slope estimates).

\section{Model Specification}

There is still some degree of debate on the use of ordinal type responses over the simpler continuous response type. The use of linear regression models (LRM) for dependent ordinal variables is still widely used in the mitigation literature (Howe, 2011; Peacock et al., 2005) as well as in the general literature, where debate over this topic is covered extensively by Winship and Mare (1984). The evidence for use of ORM over LRM is in general based on two arguments, a violation of the assumptions of LRM and simulations were use of LRM give misleading results. Long (1997) notes that the only situation were the use of ordinal dependent variables as interval would be under the assumption that the intervals between each $\mathrm{J}-1$ categories is equal. The oft-cited Jaccard and Wan (1996) justifies use of the OLS by noting that

departures from intervals did not affect Type I and Type II errors. In examining consumer satisfaction surveys Peel et al. (1998) find that fitting OLS models to 
ordinal responses leads to over inflated $R^{2}$, biased coefficients and often incorrect size and significant levels. Further, they find that the OLS model has particularly poor predictive abilities.

\section{Link function selection}

Analysis of ordered categorical choices via a generalized linear model requires a link specification for ORM estimation. The selection of link function for the ORM is still somewhat underrepresented in the literature (Greene and Hensher, 2010). Often selection is based on ease of coefficient interpretation (ordered logistic), latent variable methodology (probit), or simply norms within the particular field (ordered logistic within the bio-assay literature). Hahn and Soyer (2005) provide one of the few analysis in the literature to test between the two most popular distributional types: logit and probit. Using Bayesian specifications (DIC $\bar{D}$ ) they find limited evidence for better fits among the two distributions but only under certain specific conditions including extreme independent variable levels and in random effects model fits. Greene and Hensher (2010) gives an excellent example to counter the motivation for using sample proportions of the dependent variable to choose the correct link function for an ordered choice model.

We implement our ordered choice regression models based on the logistic link function, and in particular a variant of the ORM the "Proportional Odds model"(POM) proposed by McCullagh (1980). This popular form of the ordinal logistic model class, allows for use of the odds ratio (OR) interpretation for covariates, which assumes the $\log$ odds that $Y \geq j(\mathrm{j}=1,2, \ldots \mathrm{J})$ is linearly related to each $\mathrm{X}$ (Harrell, 2001). There is both a well established literature in particular for the study of mitigation 
and policy analysis using the POM, as well as set a of robust tools implemented in multiple software packages.

Proportional Odds and Partial Proportional Odds Models

The Proportional Odds model ${ }^{2}$ :

$$
\begin{aligned}
\operatorname{logit}[P(Y \leq j)]=\log & \frac{P(Y \leq j)}{1-P(Y \leq j)}=\alpha_{j}-\boldsymbol{\beta}^{\prime} \mathbf{x}_{\mathbf{i}} \\
& \\
& i=1,2, \cdots, N, \quad j=1,2, \cdots, J-1
\end{aligned}
$$

By stating the POM as (2.6) we are inferring that for a positive $\beta_{j}$ and an increase in covariate $X_{i}$ would correspond to increasing odds for a higher category of $Y_{i}$. At this point we make two notes of our POM before continuing. We first note that our intercept $\alpha_{j}$ (often referred to as a cut point or threshold) corresponds to each individual $\mathrm{j}$ category, in contrast with our coefficient $\boldsymbol{\beta}$ which is independent of $\mathrm{j}$. This assumption of a constant effect across all $\mathrm{J}$ categories for each $\beta_{k},(k=1,2, \ldots, p)$ is referred to as the parallel regression assumption and for particular specifications of our model must be tested (see below). Our second note, is that in general estimates of the model are based on testing assumptions of our $\boldsymbol{\beta}$ and the $\alpha_{j}$ are of little interest and therefore will not be mentioned for the remainder of the analysis.

\footnotetext{
${ }^{2}$ There is some ambiguity in how the POM is stated. We have found that the three most common forms are (1) $\operatorname{logit}(P(Y \leq j))=\beta_{0_{j}}+\beta_{1} X_{1}+\cdots+\beta_{p} X_{p} \quad(\mathrm{j}=1, \ldots, \mathrm{J}-1)$, (2) $\operatorname{logit}(P(Y \leq j))=\beta_{0_{j}}-\left(\beta_{1} X_{1}+\cdots+\beta_{p} X_{p}\right)(\mathrm{j}=1, \ldots, \mathrm{J}-1)$, and (3) $\operatorname{logit}(P(Y \geq j)=$ $\beta_{0_{j}}+\beta_{1} X_{1}+\cdots+\beta_{p} X_{p}(\mathrm{j}=2, \ldots, \mathrm{J})$. This notational issue is further confused by the fact that each software package for ORM uses a different variant of the above, which can result in output with different signs and/or interpretation. For our estimation in $\mathrm{R}$ all three packages implemented used either (2) or (3). We will use (2) for the remainder of this analysis, and make notations if the software output uses a different formula.
} 
Assumptions

An implicit assumption of the POM is of parallel regressions (Long, 1997). As noted previously, from (2.2) our cumulative distribution $F$ is evaluated where all $\beta_{1, k}=\beta_{2, k}=\ldots=\beta_{j-1, k}(k=1,2, \ldots, p)$. In other words we assume that the effect of $\boldsymbol{\beta}_{k}$ is the same for all $\mathrm{J}-1$ categories. This is akin to running $\mathrm{J}-1$ binary regressions with all slopes being identical for each $\mathrm{k}$. Once the ORM is fit by either probit or logistic distributions, a test for consistency among the $\hat{\beta}_{1}, \hat{\beta}_{2}, \ldots, \hat{\beta}_{J-1}$ estimates must be evaluated. A common option is an extension of the Wald test developed by Brant (1990). This has the advantage over a likelihood ratio or score methods in that both omnibus and simultaneous individual tests can be conducted without the need for additional models to be estimated. The Brant test statistic is asymptotically Chi-square with $(J-2) K^{3}$ df with a null hypothesis equivalent to:

$$
H_{0}: \boldsymbol{\beta}_{q}-\boldsymbol{\beta}_{1}=\mathbf{0}, q=2, \cdots, J-1
$$

Brant noted that while this test is useful for establishing support for PO model, it does not always point towards alternatives if the null is rejected. We augment our Brant test results by adopting graphical methods proposed by (Harrell et al., 1998) using separate score residuals, and plots of mean values of $\mathrm{X}$ conditional on Y. This will allow us to inspect if rejection in our test results are violations in the PO assumptions or the result of misspecification of the distributional form of the response variable.

\footnotetext{
${ }^{3}$ The degrees of freedom, $((J-1)-1) K$, for the Wald test reflect the number of rows of the contrast matrix for $H_{0}: \boldsymbol{\beta}_{1}=\cdots=\boldsymbol{\beta}_{J-1}$, and a $N \times(K+1)$ matrix $\boldsymbol{X}$ with 1's in the first column. See Long (1997) for a detailed description of the computation of the Brant Test.
} 


\section{Violation of POM assumptions}

While the POM is the most popular of the ORM used in the literature, it's assumptions are often violated and seldom tested (Capuano et al., 2007; Long, 1997). However, if parameters are tested and violations of the PO are found the practitioner now must seek an alternate and/or modification to the POM. We adopt the methods developed by Peterson and Harrell Jr (1990) who proposed an extension of the PO model called the Partial Proportional Odds Model (PPOM), which allows for a subset of non-proportional odds explanatory variables. We adapt (2.6) to allow for a subset $\mathrm{q}$ of our $\mathrm{p}$ variables $(q \leq p)$ where the PO assumption is found not to hold. For example if we allow the PO assumption to hold for coefficients $X_{1}$ and $X_{2}$, but is relaxed for the remaining q variables, we have the following:

$$
\begin{gathered}
P(Y \leq j)=\frac{1}{1+\exp \left[\alpha_{j}-\left(X_{1_{i}} \beta_{1}+X_{2_{i}} \beta_{2}+X_{3_{i}} \beta_{3_{j}} \cdots+X_{p_{i}} \beta_{p_{j}}\right)\right]}, \\
j=1,2, \cdots, J-1
\end{gathered}
$$

\section{Software}

All analysis and model fitting will be implemented via the $\mathrm{R}$ statistical programming platform. No single ORM package was found to serve all the necessary modeling and graphic techniques required, therefore the following four packages were used: Hsmic(Harrell, 2013a),ordinal(Christensen, 2013),rms(Harrell, 2013b), and VGAM(Yee, 2010). Currently the only method to implement a PPOM model in R is via the VGAM package, which was used for our final PPOM models. 


\section{CHAPTER 3 \\ SOURCES OF DATA}

\section{Survey}

Our sample data are from a 2012 survey (from May 2, 2012 to June 1, 2012) conducted by the International Hurricane Research Center (IHRC) at Florida International University. A random sample of 40,000 households, from a database of applicants for the My Safe Florida Home (MSFH) program, were contacted via email. The response rate was approximately 4.3\%, with 1,720 responses representing $69 \%$ of all of Florida's counties. The online survey consisted of five sections including 40 attitudinal and behavioral questions. Descriptive statistics and independent variables used in our models are from a variety of sections from the survey related to: demographics, housing characteristics, hurricane experience, current and future hurricane storm damage concern, and attitudinal feelings towards public and private institutions. The dependent variables used for our OR models derive from the section titled Public and Private Residential Insurance. In this section, respondents were asked a series of questions regarding their level of support for policy reform of the current public/private natural disaster residential insurance market. Responses were on a ordinal rating scale (coded 0-10) as not-supportive at all to highly supportive for survey policy questions.

\section{Sample Characteristics}

The sample was examined and cleaned by removing respondents with a significant number of missing and/or erroneous entries, which led to a $18.02 \%$ reduction. Income was missing for approximately $9 \%$ of respondents, and was the vari- 
able with the largest number of missing values. Several locational/spatial variables (County, Coastal Distance, and County Insurance Rate) were calculated based on zip code data which was missing in approximately $3 \%$ of the sample. Median age for the sample (60) is higher than the state average $(40.7)^{1}$; however as our respondents are single family homeowner this falls into the national average. The majority of respondents are Caucasian (82.5)\%, followed by Hispanic (7.3)\%, African American (4.8)\%, and all others (5.4)\%. Peacock (2003) has noted that even given Florida's diverse population, home-ownership will not mimic overall population patterns due to long-term differences in ownership rates among minorities. On average, respondents have lived in the state of Florida 29.59 years. The highest percentage of the sample reside in the southern area of Florida (Broward (12\%), Miami-Dade (9\%), and Palm Beach $(8 \%)$ counties). Estimated median income ${ }^{2}$ was $\$ 75,000$, which is higher than the state average of $\$ 47,309$.

\section{Measures}

\section{Dependent Variables}

We fit separate ordinal regression models to each of the following policy questions from our survey:

\footnotetext{
${ }^{1}$ All State data is obtained from the U.S. census 2010 Demographic Profile http://factfinder2. census.gov/faces/tableservices/jsf/pages/productview. xhtml?src=bkmk.

${ }^{2}$ Total household income was originally recorded using a 25 discretized intervals scale. We use mid-points from each interval and treat income as a continuous variable.
} 


\section{Surcharge:}

Florida funds the insurance system to pay for hurricane damage after-the-fact with surcharges, regular assessments and emergency assessments on nearly every insurance line in the state (auto, casualty and property insurance). Please note that eliminating these fees would likely cause currently subsidized insurance premiums to rise. How supportive are you of Florida continuing to finance shortfalls with surcharges, regular assessments and emergency assessments, on a scale of 0 to 10 ?

\section{Flood(5yr):}

A recent study by the University of Pennsylvania found that only $36 \%$ of new flood insurance policies issued between 2001 and 2009 were still in place five years after they were purchased. How supportive are you of multi-year (5-year) flood insurance contracts, on a scale from 0 to $10 ?$

Flood(30yr):

How supportive are you of multi-year (30-year) flood insurance contracts, on a scale from 0 to 10 ?

\section{All Hazards:}

In the aftermath of several recent hurricanes much debate was focused on whether damages were caused by flooding and should be covered under flood insurance policies or damages were caused by wind and should be covered by wind insurance policies. A comprehensive all-hazards insurance program (fire, wind, flood, tornado, earthquake), which could pool policy holders with diversified risks may create a more stabilized insurance mechanism and reduce uncertainty about the availability and affordability of coverage. On a scale from 0 to 10, how supportive are you of 
comprehensive all-hazards insurance?

\section{Catastrophic Savings:}

Tax-free household catastrophe savings accounts could permit households to establish reserves for future losses not covered by wind or flood insurance policies. How supportive are you of tax-free household catastrophe savings accounts, on a scale from 0 to 10 ?

\section{Independent Variables}

Our independent variable (IV) selection is based on a review of the literature as it relates to hurricane mitigation, risk perception, adaption behavior and policy response for homeowners in the state of Florida. Our covariates are focused on four main areas: Demographics, Housing characteristics, Hurricane experience, Risk perception, and Trust.

\section{Demographics}

A large set of the hurricane mitigation and risk perception literature incorporates several demographic variables into their analysis, along with key socioeconomic covariates as well. In particular, positive effects as relates to mitigation incentive programs were found in several characteristics including Age and Gender (female) (Ge et al., 2011; Howe, 2011; Peacock et al., 2005). Years of residence (Years FL resident) as relates to mitigation adaption behavior has been found to have mixed results, across studies. Some studies have shown positive effects for risk perception and mitigation adaption (Peacock, 2003). While others have found negative effects 
related to mitigation information (Chatterjee and Mozumder, 2014) and evacuation behaviors (Lazo et al., 2010). Another common variable from the hazard adjustment literature is household income (Income) which has been shown to have a significant effect on various mitigation behaviors. A key finding has been significant support among lower-income households for a variety of incentive programs for hurricane mitigation, with higher income groups typically more supportive of investing in structural protective measures (Ge et al., 2011; Peacock, 2003). Political affiliation is not a typical variable used in the study of mitigation or risk perception, but is prominent in the policy preference literature. While a majority of the studies focus on political partisanship as it relates to climate change policy (Hart and Nisbet, 2011), there has been been significant evidence presenting the importance of group identification and social identity on public opinion and policy preferences (Nelson and Kinder, 1996; Sniderman et al., 1993). Prater and Lindell (2000) have noted the concept of issue framing in the context of natural disaster mitigation measures in the presence of various political agendas. We include a covariate for party affiliation (Poltical) in our model to measure possible framing effects for support of policy change.

\section{Housing Characteristics}

As respondents were asked only minimal locational information (other than zip code information) we use several covariates (Wind Policy, Flood Policy, Coastal Distance, and County Insurance Rate) to measure a homeowner's hazard proximity. We create a variable measuring distance from the centroid of the respondent's zip code to the nearest coastal zone. A positive (inversely proportional) effect should be seen for distance to coastal regions. We augment our data set with additional county 
level data for average homeowners insurance rates (County Insurance Rate) ${ }^{3}$. Cole et al. (2011) consider a similar data set (2009 data Florida homeowners insurance rates) found significant evidence of a subsidy for coastal residents whereby inland residents rates were higher than under a risk based assessment structure. Here we aggregate all private insurers per county to create an index of property insurance rates regardless of purchase. Purchase of Flood insurance in the state of Florida is a mix of mandatory and voluntary which is based on location as prespecfied by FEMA. Examining flood insurance demand from 2000-2005 in the state of Florida, Kunreuther and Michel-Kerjan (2009) found approximately $18 \%$ of all residential single-family polices in force were for non-mandatory areas (Flood zone X), and roughly $75 \%$ of policies found in the mandatory areas (Flood zone A). The role of risk aversion and future expected storm damage have been both found to have a positive impact on flood insurance demand (Petrolia et al., 2011). Additionally we are interested in measuring preferences of current flood insurance purchasers for reform of the current flood insurance market (DV's: Flood(5yr) and Flood(30yr)). Wind storm insurance purchase is likewise a mix of mandatory and volunteer purchasers. Florida law requires all property insurance policies to include for this type of coverage and purchase is mandatory for homeowners with a mortgage, as stipulated for underwriting purposes.

\section{Hurricane Experience}

Hurricane experience as a predictor for mitigation and storm evacuation has been inconclusive in the literature. Respondents in our sample had a median number of

\footnotetext{
${ }^{3}$ Data is based on Florida Office of Insurance Regulation estimates and measures risk for a Florida masonry home built in 2005 , with a current replacement value of $\$ 300,000$, a $\$ 500$ non-hurricane deductible, a $2 \%$ hurricane deductible, no claims in the past three years, and minimum premium discounts for limited wind mitigation features and no hip roof.
} 
one significant hurricane damage experience, with $22.6 \%$ of the study having greater than one. Due to the relatively low percentage of total hurricane experience we instead construct a storm damage total variable (Storm Damage), which sums the total interior and exterior damage a respondent has incurred on their property from a hurricane. We hypothesize that households with higher levels of storm damage totals will be more supportive of the status quo policy for Surcharge, as those respondents may associate a fully risk-based system as potentially negatively affecting coverage as well as higher premiums. The remainder of the policy questions are hypothesized to be positively correlated with storm damage.

\section{Risk perception}

The literature focusing on hurricane risk perception and it's relationship with hazard mitigation is extensive. Ge et al. (2011) examined Florida household's response to a series of incentive programs and found risk perception to be the most consistently significant predictor of support. In estimating structural mitigation measures of Florida households, hurricane risk perception was found to be highly significant (Peacock, 2003). We create two likert scale responses (Storm Concern (1yr), Storm Concern (10yr)) based on a particular time horizon to measure a household's perception of hurricane risk. Each respondent was asked there level of concern (scale 0-10) of a major hurricane damaging their home this hurricane season and over the next 10 years. Additionally, each question was asked again but this time specifying a damage rate of more than $10 \%$ of the home's value. Respondents showed significantly higher levels of concern for potential damage within 10 years versus the coming hurricane season (Wilcoxon rank sum, $p<.001$ ). Within the context of our various policy reforms we hypothesize potentially mixed finding. Our Surcharge asks for support for the current subsidy-type assessment over a risk based one. There- 
fore, households with higher levels of current concern may be more incentivized to support the status quo, due to uncertainty over impacts to their current rates.

Trust

A respondents feelings toward reform is considered multi-dimensional, with worry over effective implementation a major cause of concern (Frewer, 1999). Because laypersons are less likely to have specific knowledge of risk management and hazard mitigation strategies, their assessments of policy reform will be based on trust in technical and policy experts (Siegrist and Cvetkovich, 2000). Respondents in our sample were asked to rate the accountability of four tiers of public institutions (City, County, State, and Federal) and private insurance companies on a 0-10 scale. We are interested in measuring the level of social trust that households assign to these various governmental and private organizations. Trust in these institutions is hypothesized to be positively associated with support for policy reforms. 


\section{CHAPTER 4}

\section{DATA ANALYSIS AND RESULTS}

\section{Data Analysis}

\section{Dependent Variable}

Table 4.1 shows the raw distribution of each individual policy question, to allow for visual inspection of potential trends. Surcharge shows clustering among the extreme values as well as the neutral position $(=6)$. We note that responses tend to cluster around neutral and the extreme points for the Surcharge, Flood(5yr), Flood(30yr). A clear trend in support for the All Hazards, and Catastrophic Savings questions can be seen from the graphs. The strong support for All Hazards suggests that respondents maybe associating a higher cost with policy maintenance and therefore value simplification of natural disaster insurance coverage. Further within the context of the other questions and given the high rate of natural disaster insurance rates within our sample ${ }^{1}$, All Hazards posses the highest net benefit relative to implied cost.

\section{Independent Variable}

We next examine our independent variables for potential collinearity, or variable redundancies. The continuous and ordinal scale variables were examined via a matrix of squared Spearman correlation coefficients, which allows for monotonic non-linear relationships to be assessed. Figure 4.2 is a dendrogram of our hierarchical cluster analysis $^{2}$ with Spearman's $\rho^{2}$. Many of our housing characteristic variables (Insur-

\footnotetext{
${ }^{1}$ For the total sample $(\mathrm{N}=1394)$, approximately $81.9 \%$ had Property insurance and at least one other type of insurance (flood or wind).

${ }^{2}$ Our cluster analysis is based on the complete-linkage method in the R package hclust.
} 
Figure 4.1: Distribution of Policy Question Responses (1=Not supportive, $11=$ Highly Supportive)
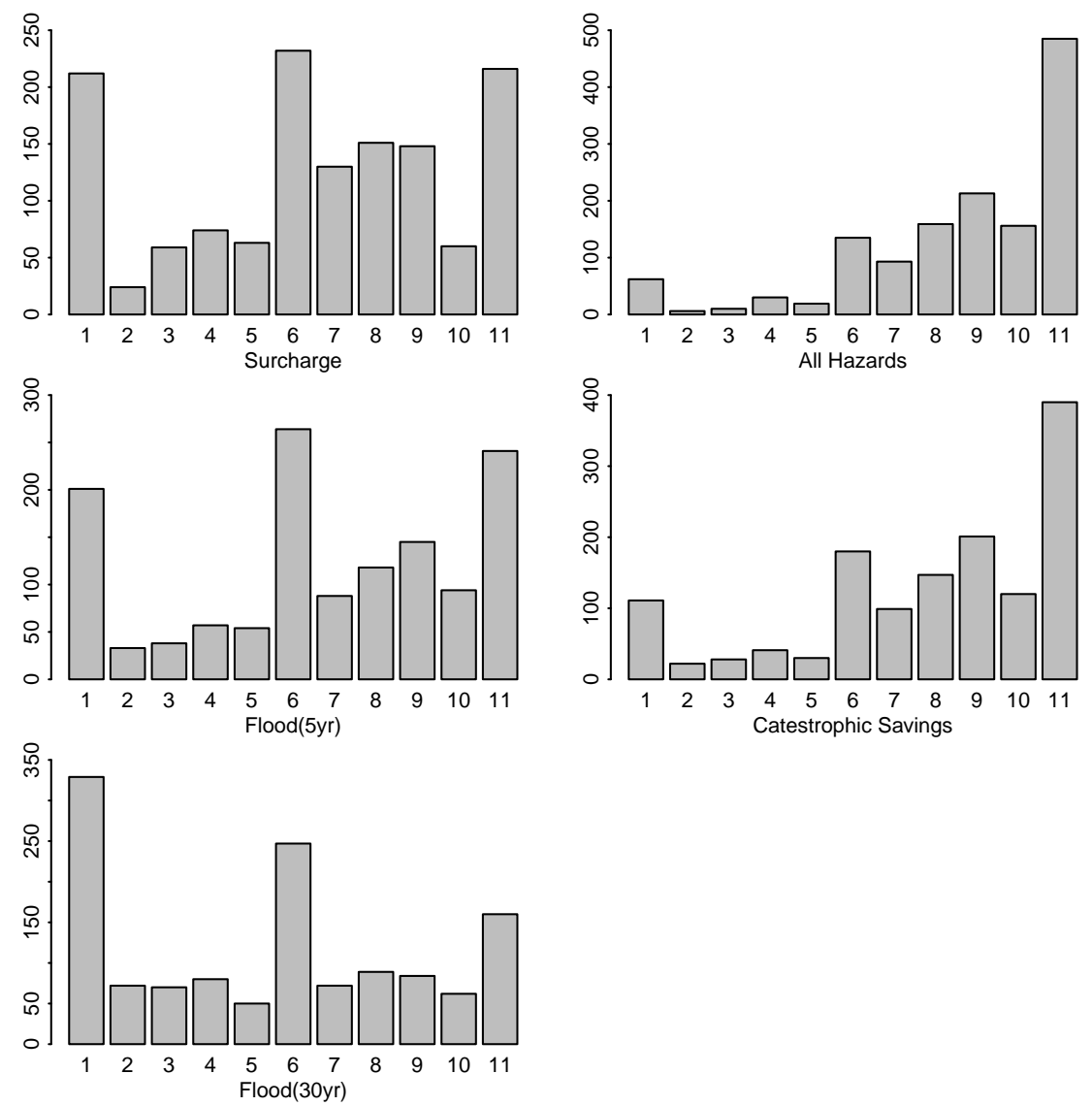
Figure 4.2: Cluster Analysis of Independent Variables

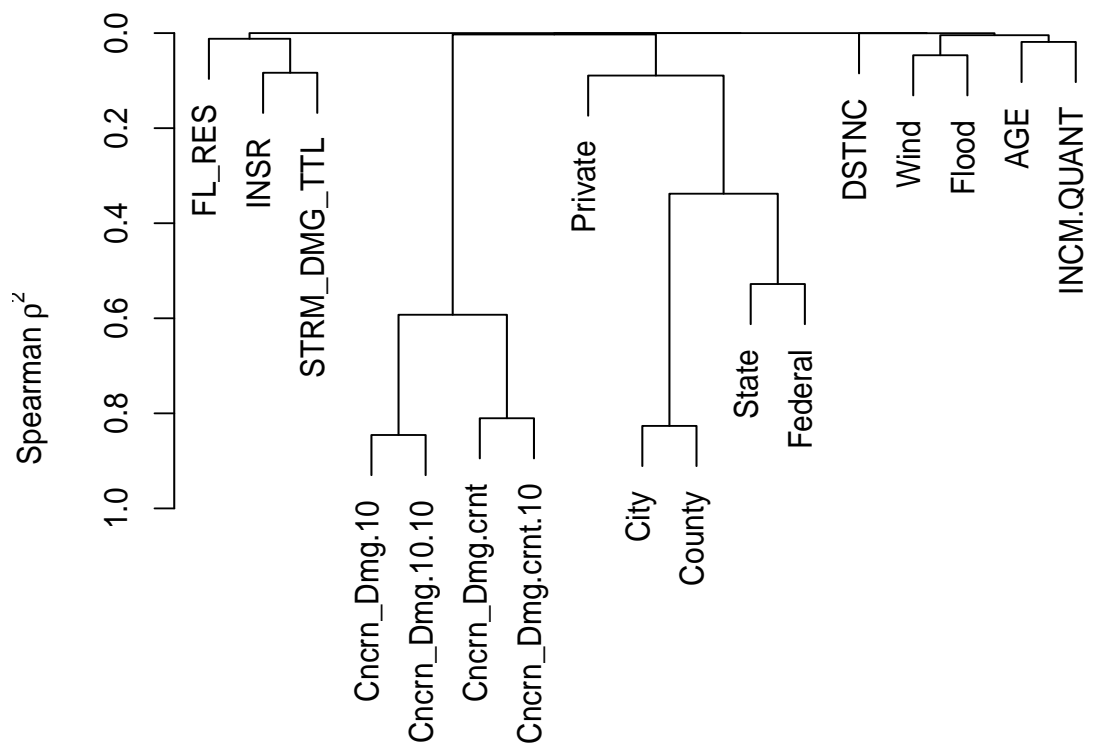

ance rate, Insurance coverage types, total storm damage) tend to belong to their logical clusters. For example from our second to the left cluster, Insurance Rate and Storm Damage Total, we would expect single family homeowners in Florida with higher insurance rates to have experienced a higher rate of hurricane storm damage. Our clusters of concern variables have significant $\rho^{2}$ (see vertical axis on Figure 4.2) which suggests that some degree of multi-collinearity could cause potential issues if our model is fit with all four variables. Variables which measure a respondents trust of public institutions reveals clusters based on typical governmental tier system. Differences among trust of public institutions (City, County, State and Federal) is not significant $(5.99, \mathrm{p}>.10)$. However testing for differences in trust for public institutions versus private insurance companies is significant (pairwise Wilcoxon rank 
sum test with Bonferroni adjustment, all $\mathrm{p}<.05)$. Respondents show significantly higher levels of trust in Private Insurance companies on average (Median=7) than for public governmental institutions (Median=6, for all). Based on correlation/cluster analysis we create one new variables based on our governmental tier clusters. As our Trust responses are Likert items measured on the same scale we sum their values into our variable Trust(Public Institutions). Concern clusters are summed as well to create two new Likert scale variables, Storm Concern (1yr), and Storm Concern (10yr). Further variable reduction was deemed unwarranted based on the potential loss of specific coefficient estimates from continued variable clustering.

\section{Model Fitting}

\section{Proportional Odds Model}

Before testing ORM assumptions of our initial model, we adopt the procedure suggested by Harrell (2001), and check via a graphical method. The assumptions of ordinality and Proportional Odds (PO) were checked by plotting each of the five policy questions against our set of individual predictors. One of the main assumptions of the standard ORM is an ordered relationship between responses and each individual covariate. The PO assumption was assessed by finding the expected value $(\mathrm{E}(\mathrm{X} \mid \mathrm{Y}=\mathrm{j}))$ for each of our $\mathrm{J}=11$ categories, given that PO holds. Graphically this allows us to examine differences in our mean $\mathrm{X}$ to their respective expected values if the PO assumption holds. Our graphical analysis showed a significant number of predictors did not meet the PO assumption, with some values constant across each of the $\mathrm{J}=11$ categories. However a majority of expected values did show a decreasing or increasing trend given that our PO assumption held for all questions except for All Hazards (see below for discussion). 
We adopted the ordinal regression model building strategy outlined in Hosmer Jr and Lemeshow (2004) and ran separate univariate models for each covariate. Significant level thresholds were set at a higher than usual level (.20) to allow for prospective significant main effects in the full multivariate model. The Akaike information criterion (AIC) was calculated for each model which allowed for the largest maximum likelihood value estimates to be rewarded while at the same time penalizing for additional variables in the main effects model. At this point low $(<1 \%)$ and no cell counts were identified among several of the variables (Political, Storm Concern (1yr), and Income). Issues with zero-cell counts and/or low response rates in the outcome variable have been found to lead to spuriously high chi-square values in global non-proportionality tests as well as model convergence issues (Christensen, 2011; Peterson and Harrell Jr, 1990; Scott et al., 1997). We tested for potential model convergence issues related to cell count deficiencies by running initial separate and full main effects multivariate regressions on all five of our policy questions. Our condition number of the Hessian (the ratio of the maximum and minimum eigenvalue) for each model was found to be high $\left(>10^{6}\right)$ suggesting potential model convergence issues(Christensen, 2011). Further, significant numerical estimation problems were found in the initial model building stages with several non-proportionality tests failing to converge. At this point we adopted the method suggested by Strömberg (1996) and collapsed our 11 pt response type into a new 5 point scale ${ }^{3}$.

All five point models were significant ( $\left.\operatorname{LR} \chi^{2} \mathrm{p}<.001\right)$, and a decrease in the condition number for each model's Hessian matrix suggested a better fit. AIC's for all 5pt models were smaller than their corresponding 11pt counterparts and our graphical analysis of the PO assumptions for the 5pt model showed a signif-

\footnotetext{
${ }^{3}$ Following a data-driven approach, we collapsed the 11 point response scale into a five point type as the following: $1=1-2,2=3-4,3=5-7,4=8-9,5=10-11$.
} 
Table 4.1: UNIVARIATE PO MODELS

\begin{tabular}{rlllll}
\hline & Surcharge & Flood(5yr) & Flood(30yr) & All Hazards & Catastrophic Savings $^{\mathrm{a}}$ \\
\hline Male & $-0.523^{\mathrm{a}}$ & $-0.247^{\mathrm{c}}$ & 0.125 & -0.153 & -0.055 \\
Age & 0.003 & 0.001 & $-0.013^{\mathrm{c}}$ & 0.006 & $-0.011^{\mathrm{c}}$ \\
FL Resident(Years) & 0.002 & $-0.006^{\mathrm{d}}$ & $-0.008^{\mathrm{c}}$ & $-0.007^{\mathrm{d}}$ & 0.002 \\
Democratic & $0.615^{\mathrm{a}}$ & 0.218 & 0.036 & $0.461^{\mathrm{b}}$ & 0.19 \\
Independent & $0.622^{\mathrm{a}}$ & 0.243 & 0.166 & $0.581^{\mathrm{b}}$ & 0.258 \\
Other & $0.274^{\mathrm{d}}$ & -0.166 & -0.084 & 0.042 & 0.222 \\
Income & -0.001 & $0.004^{\mathrm{a}}$ & $0.003^{\mathrm{c}}$ & 0 & $0.002^{\mathrm{d}}$ \\
Wind Policy & $0.244^{\mathrm{c}}$ & 0.201 & $0.204^{\mathrm{d}}$ & 0.086 & 0.058 \\
Flood Policy & $0.462^{\mathrm{a}}$ & $0.453^{\mathrm{a}}$ & -0.084 & $0.279^{\mathrm{c}}$ & 0.099 \\
Distance & $-0.024^{\mathrm{c}}$ & -0.008 & 0.008 & $-0.02^{\mathrm{c}}$ & $-0.029^{\mathrm{b}}$ \\
Insurance Rate & $0.144^{\mathrm{a}}$ & 0.052 & -0.029 & $0.13^{\mathrm{a}}$ & $0.136^{\mathrm{a}}$ \\
Storm Damage Total & $0.059^{\mathrm{b}}$ & 0.025 & 0.034 & 0.027 & $0.07^{\mathrm{b}}$ \\
Concern 1yr & $0.072^{\mathrm{a}}$ & $0.039^{\mathrm{a}}$ & $0.025^{\mathrm{c}}$ & $0.041^{\mathrm{a}}$ & $0.036^{\mathrm{a}}$ \\
Concern 10yr & $0.062^{\mathrm{a}}$ & $0.045^{\mathrm{a}}$ & $0.029^{\mathrm{b}}$ & $0.039^{\mathrm{a}}$ & $0.028^{\mathrm{b}}$ \\
Private Trust & $0.043^{\mathrm{c}}$ & 0.022 & 0.017 & -0.005 & $0.031^{\mathrm{d}}$ \\
Public Trust & $0.056^{\mathrm{a}}$ & $0.03^{\mathrm{a}}$ & $0.02^{\mathrm{a}}$ & $0.014^{\mathrm{c}}$ & $0.022^{\mathrm{a}}$ \\
\hline
\end{tabular}

${ }^{\mathrm{a}} \mathrm{p}<.001 ;^{\mathrm{b}} \mathrm{p}<.01 ;^{\mathrm{c}} \mathrm{p}<.05$

icant improvement for several variables ( Surcharge:Male, Storm Concern (1yr); Flood(5yr):Trust(Public Institutions),Storm Concern (1yr); Flood(30yr): Storm Concern (1yr), Storm Concern (10yr); Catastrophic Savings:Age, County Insurance Rate, Storm Damage, Storm Concern (1yr), Trust(Public Institutions)) however several seemed to still be problematic in terms of the PO assumption. Based on improvements in fit, smoothing of likely PO conflicts, and general desire for model parsimonious we moved forward with the 5pt response type. All variables used in the main effects models were significant for at least two of the policy questions in our univariate analysis or considered relevant based on the literature review.

Our final model fitting strategy was to test the PO model assumption via the Brant test ${ }^{4}$ for each of our covariates at each policy response. We implement our Brant test to assess the overall PO assumption as well as individual coefficient estimates as well and a pre-specified 10\% significance level was set as our criteria.

\footnotetext{
${ }^{4}$ The Brant Test is currently not implemented in $\mathrm{R}$, therefore our test was run in STATA. All coefficients from each model were checked for consistency and found to be within minimum tolerance (<.001 absolute difference).
} 
Table 4.2: Proportional Odds Models

\begin{tabular}{rlllll}
\hline & Surcharge & Flood(5yr) & Flood(30yr) & All Hazards & Catastrophic Savings \\
\hline Male & $-0.372^{\mathrm{b}}$ & $-0.277^{\mathrm{c}}$ & 0.165 & -0.057 & 0.061 \\
Age & 0.008 & 0.004 & $-0.014^{\mathrm{b}}$ & 0.008 & $-0.009^{\mathrm{d}}$ \\
Years FL resident & -0.001 & $-0.008^{\mathrm{c}}$ & $-0.008^{\mathrm{c}}$ & $-0.009^{\mathrm{c}}$ & 0.001 \\
Political(Democrat) & $0.279^{\mathrm{d}}$ & 0.058 & 0.04 & $0.305^{\mathrm{c}}$ & 0.075 \\
Political(Independent) & $0.466^{\mathrm{b}}$ & 0.11 & 0.134 & $0.436^{\mathrm{c}}$ & 0.214 \\
Political(Other) & 0.196 & -0.24 & -0.12 & -0.074 & 0.156 \\
Income & -0.001 & $0.005^{\mathrm{a}}$ & $0.003^{\mathrm{c}}$ & 0 & $0.002^{\mathrm{c}}$ \\
Wind Policy & 0.159 & 0.175 & $0.298^{\mathrm{c}}$ & -0.029 & -0.007 \\
Flood Policy & $0.38^{\mathrm{b}}$ & $0.34^{\mathrm{b}}$ & -0.164 & 0.156 & -0.033 \\
Coastal Distance & -0.015 & 0 & 0.003 & -0.008 & $-0.025^{\mathrm{c}}$ \\
County Insurance Rate & 0.055 & 0 & -0.056 & $0.106^{\mathrm{c}}$ & $0.07^{\mathrm{d}}$ \\
Storm Damage & 0.025 & 0.015 & $0.045^{\mathrm{d}}$ & 0.001 & $0.052^{\mathrm{c}}$ \\
Storm Concern (1yr) & $0.039^{\mathrm{c}}$ & -0.001 & 0.003 & 0.02 & 0.029 \\
Storm Concern (10yr) & 0.011 & $0.04^{\mathrm{c}}$ & 0.022 & 0.017 & -0.004 \\
Trust(Public Institutions) & $0.056^{\mathrm{a}}$ & $0.033^{\mathrm{a}}$ & $0.022^{\mathrm{a}}$ & $0.015^{\mathrm{c}}$ & $0.019^{\mathrm{b}}$ \\
Trust(Private Institutions) & -0.028 & -0.019 & -0.013 & -0.026 & 0.006 \\
Log L & -1413.473 & -1434.812 & -1461.756 & -1210.324 & -1350.189 \\
LR $\chi^{2}$ & 174.728 & 88.848 & 50.739 & 52.607 & 52.889 \\
AIC & 2866.946 & 2909.623 & 2963.511 & 2460.649 & 2740.379
\end{tabular}

The results from each overall test ${ }^{5}\left(H_{0}=\boldsymbol{\beta}_{1}=\boldsymbol{\beta}_{2}=\cdots=\boldsymbol{\beta}_{J-1}\right)$ show that several of our policy responses fail the PO assumption (Surcharge, Flood(5yr), and Flood(30yr), p<.10 for all). Once the model was deemed to have failed the PO assumption, individual coefficients were assessed. The null hypothesis for the kth variable from our 5 questions $H_{0}=\beta_{k, 1}=\beta_{k, 2}=\cdots=\beta_{k, J-1}{ }^{6}$, is tested in a similar manner as our overall test, with J-2 df. Surcharge had the largest number of significant coefficients (5), followed by Flood(30yr) (4). Two of our questions, All Hazards and Catastrophic Savings, were non-significant for the Brant omnibus test. However after examining individual tests and referencing our initial graphical analysis we find evidence to suggest some variable violate the PO assumption.

${ }^{5}$ See Long (1997) for a detailed description of the computation of the Brant Test.

${ }^{6}$ Note that we are not using vector notation as individual variable tests are constructed by taking the appropriate columns and rows from the matrices required to compute our omnibus test. 


\section{Partial Proportional Odds Model}

Based on the results from our Brant test and graphical analysis we relaxed the PO assumption for multiple variables. Omnibus variable selection was not selected as an appropriate method for all five questions. Instead we allow a variable's PO assumption to be relaxed on a per question basis. This is based on both our test results and our hypothesis that some variables will act in a heterogeneous manner across policy questions. We implement the PPOM fit via the VGAM (Yee, 2010) package, to estimate models for each of our five DV's. Estimates of AIC were included in order to test for differences between our PO and PPO models. No single variable was found to fail the PO assumption across all policy questions.

\section{Results}

All models $(\mathrm{PO}$ and PPO) were significant $(\mathrm{p}<.001)$ by the likelihood ratio test of nested models, which suggests our models are an improvement over a simple null only model (i.e., on with no predictors). Comparing AIC for PO and PPO models we find reductions in all responses except for All Hazards which shows only a $.2 \%$ increase. Likelihood ratio tests were implemented to compare PO versus PPO models for each response. All LR test rejected the null hypothesis that our POM is nested in the PPOM (all models $\mathrm{p}<.10$ ), which indicates that our PO model is too restrictive. The PPOM has significantly increased our likelihood, and therefore represents a better fit.

\section{Surcharge}

The results from our PO model for policy response question Surcharge suggest that present concern (Storm Concern (1yr)) is a significant predictor of support for the 
status quo Surcharge policy. Single family homeowners with higher levels of present 1 year concern about hurricane damage have a significantly higher probability of supporting the current surcharge subsidy policy $(\mathrm{p}<.05)$. This implies respondents in higher risk areas consider changes to the current insurance market as potentially negative. Zip code analysis of respondents with the strongest support (5) for Surcharge conditional on being from the $>75 \%$ quantile of Storm Concern (1yr) are from regions that had recent Hurricane activity (Wilma) and high risk areas (coastal South Florida). Trust(Public Institutions) is also significant $(\mathrm{p}<.001)$ for support of status-quo policy support. If we contrast this finding with the negative coefficient $(\mathrm{p}>.10)$ for trust in Private institutions implies respondents identify the removal of surcharge system as a move from state-backed subsidy system to one that is more market based. Respondents who self-identify politically as Democratic or Independent have a significantly higher probability of support for Surcharge (base level=Republicans).

The Brant test results showed that two of our significant variables (Storm Concern (1yr) and Trust(Public Institutions)) failed the PO assumption. We tested all variables including those found to be non-significant in the PO model. The PPO model showed significance in previously non-significant variables (Wind Policy, County Insurance Rate and Storm Concern (10yr)) for particular levels of Surcharge. The Wind insurance purchase $(\mathrm{N}=663)$ covariate was found to be non-significant $(\mathrm{p}>.10)$ in our PO. However via the PPO Windstorm Insurance purchasers have predicted odds of higher levels of support $(P \geq 4)$ versus less supportive $(\mathrm{O} . \mathrm{R}=1.58)$ of the status quo are significant at only that level. In contrast Flood Policy $(\mathrm{N}=581)$ have a significant higher odds (O.R.=1.47) of supporting Surcharge at increasing levels, for both PO and PPO models. By implementing the PPOM we find some covariates are not consistently significant at higher levels as suggested by our PO 
model. Our PPOM results suggest that Storm Concern (1yr) is only significant at lower levels of support for Surcharge. Our predicted odds suggest an increasing support for Surcharge only to a neutral preference.

Flood(5yr)

Our PO model results show minimal but significant decreasing odds of support for changes to the current national flood insurance policy for increasing years of Florida residency. This is consistent throughout our policy responses, suggesting evidence for an increasing "status quo" effect for residency status. Statistical significant increasing support for Flood(5yr) in Storm Concern (10yr) (O.R.=1.04) implies respondents are making mitigating preferences in order to decrease costs associated with potential future hurricane and storm damage. Increasing trust in Public Institutions is positive in predictive odds for support of Flood(5yr), which contrasts with Surcharge increasing support for the status quo. PO assumption were violated in one of our significant variables, Flood Policy. After our PPO model was fit, we find policy holders of Flood insurance to have significantly higher levels of support for changes to the current national flood insurance market by implementing mandatory 5-yr contracts for all policy holders. This could reflect current policy holders lower perceived cost associated with such a policy change (i.e., expected policy period may be already estimated beyond the 5 year term). The positive coefficient for Income ${ }^{7}$ indicates that for every unit increase, the predicted odds of support for Flood(5yr) is positive.

Flood(30yr)

Using our results from Flood(5yr) we find several covariates are consistent for increasing mandatory flood contract to a 30 year term. Also, with the exception of

\footnotetext{
${ }^{7}$ Income coefficient reflects a change per $\$ 1000$.
} 
Age, non-proportional covariates are consistent across the two flood policy questions. In particular after fitting the PPOM is the positive coefficient for Income (here only a slight decrease in the odds ratio to 1.03) and the decreasing odds of support by years of Florida residency. Trust in Public institutions continues to be significant across all policy questions. We note that flood insurance does not continue to be as significant and is negative for several levels of the Flood(5yr) response. This suggests that 30yr flood terms may have exceed estimated policy period held by respondents.

Supporting evidence of this is found by examining the negative coefficients for Age which reflects the decreasing odds of support at all levels of Flood(30yr). In contrast to our Flood(5yr)model, wind storm policy purchasers are found to have significant positive predictive odds for supporting the longer-term period.

\section{All Hazards}

As noted previously we find strong support for an All Hazards type insurance policy, with responses associated with support representing $74.2 \%$ of the total. The results from the initial PO model show the continued "status quo" effect for increasing years of Florida residency, although at only a minimal level. Higher county wide average insurance rebuild rates (County Insurance Rate) are significant in positive predictive odds $(\mathrm{O} . \mathrm{R}=1.11)$ for support. This suggests homeowners associate a bundling of insurance products as potentially cost minimizing. Respondents who self-identified as Democratic or Independent both show positive increasing support at each level of All Hazards, when compared with the political reference level of Republican.

The Brant omnibus and individual test(s) were non-significant which contrasted with our initial graphical analysis (see discussion below) which showed several variables failing the PO assumption. Using results from our graphical analysis, and examining coefficients from 4 (j-1) binary regressions on our All Hazards response 
we fit a PPO model with Male, Years FL resident, and Coastal Distance as non-PO covariates. Age is found to be positively affecting policy support but only at the highest level $(\mathrm{P}(\mathrm{Y}>4)$ and we note an increasing monotonic scale effect across levels. Trust (Public Institutions) is again positively affecting policy change support.

\section{Catastrophic Savings}

Coefficients of several variables are found to be significant with the assumed signs in our initial PO model. For example Income is positively predictive of support for tax free savings accounts. While our findings from the omnibus Brant test were non-significant a graphical examination of plots and coefficient estimates from a series of binary fits found one variable (Wind Policy) to have potential not met the proportional odds criteria. Therefore Wind Policy was entered into the PPOM as a non-proportional odds explanatory variable. Coefficients were consistent in their sign and significance in the the PPOM. 


\section{CHAPTER 5 \\ CONCLUSION}

\section{Findings}

The fiscal instability in natural disaster mitigation financing has become of paramount importance for policy makers on both federal and state level. We began this paper by showing the significant issues that policy makers face at both the national and regional levels after a series of natural disasters. While some policy makers have moved forward legislation to correct long-term financing issues in the property insurance market, they have been meet with significant backlash from constituents. Using survey results from single family homeowners in the state of Florida, we have examined many of the factors that may contribute to support for reforms in the property insurance market place. Our analysis suggests that Florida's homeowners are supportive of Federal comprehensive insurance as well as tax deferred savings for storm damage expenses. However we find that many homeowners are supportive of the status quo and are averse to meaningful reforms. These factors are potentially contributing to backlash against recent reforms such as 2012 Biggert-Waters Act.

Our findings suggest that a significant status quo effect among long time Florida residents could be deterring changes to the current system. For four of the five policy questions surveyed, we find Florida residents with higher years of residency to be less supportive of changes or neutral. In general we find Florida homeowners in this study to be neutral on policy questions: Surcharge, Flood(5yr), Flood(30yr). Under the framework of a "status quo" effect suggests residents do not associate these reform measures to be efficiency-enhancing and/or lack information to state a preference. While our survey instrument does not include a specific Biggert-Water Act question, we can infer that the Surcharge question most closely resembles some of the reforms 
laid out in the legislation. Therefore residents preference may have shifted from an initial neutral stance to a negative position post-Bigger-Waters passage, when potential rate increase information was reveled.

Results from our five individual models show significant effects of Trust(Public Institutions) as a predictor of support for policy reforms. We observe strong support for the current insurance mechanism in Surcharge, but moderate support for reforms in Flood(5yr), Flood(30yr), All Hazards, and Catastrophic Savings as well. We hypothesize that homeowners with higher levels of trust in government may consider the current funding system for hurricane damage as enacted by the state government, to be the most optimal. Further research could investigate this result.

Individual results from each of the policy responses show a variety of significant factors contributing to households preference. We find evidence to support our hypothesis that higher risk perception among homeowner's will lead to higher levels of endorsement for Florida's current insurance system to pay for hurricane damage. Responses to Surcharge show that Flood policy holders with homes located in higher insurance rebuild areas have significant support for the current system. This suggests that households in risky areas are estimating higher premiums associated with a removal of a surcharge funding mechanism. There is, however, significant support among Flood policy holders for multi-year 5yr contracts (Flood(5yr)). Because this support does not continue with 30 year contracts (Flood(30yr)), our data set suggests that households with flood insurance are estimating continued purchase in between these potential contract terms. Further research could help identify preferred contract terms for current and future flood policy holders. Support for both longer term contracts was found to be significant for higher household income levels. This conforms to our previous hypothesis that increasing income will have a higher willingness to pay for mitigation measures. 
Respondents were, on average, more favorable towards a Comprehensive Allhazards type insurance program as well as tax deferred savings accounts to establish reserves for future storm-damage losses. Our model had somewhat mixed results in identifying strong predictors for support of either question. Respondents residing in coastal counties, and those with higher levels of Income had significant positive support for a Catastrophic Savings type account. This agrees with our previous hypothesis that homeowners' income levels are positively correlated with savings rates. Here we can infer that homeowners with higher incomes may also be more incentivized to be supportive of tax reduction policies. Homeowners with higher levels of previous Storm Damage and County Insurance Rate are also positively supportive of Catastrophic Savings, inferring that households are interested in alternative non-insurance type instruments to allow for hurricane mitigation. Our findings for County Insurance Rate in Catastrophic Savings and All Hazards suggest that homeowners with higher levels of insurance rebuild rates may consider these two policies as cost reduction strategies. Negative effects are found for Coastal Distance so that approximately every 10 mile increase in the distance to a coastal body respondents are $-76.4 \%$ likely to have increasing levels of support for Catastrophic Savings. Initial univariate analysis of our covariates found significant (negative) correlation between County Insurance Rate and Coastal Distance $(\mathrm{r}=-0.287, \mathrm{p}<.001)$, which is consistent in this model.

\section{Potential Limitations}

Therefore we outline some of the potential limitations of this analysis which may aid in future research. Florida contains a diverse number of residential properties of which single family housing is a significant percentage. As coastal properties in Florida tend to be condominium and townhouse owners, we recognize that our 
sample excludes some of the highest risk policy holders who could see the largest rate increases if the current surcharge funding insurance structure were removed.

We also note that our sample is predominately Caucasian, and while somewhat representative of the single family homeowners, does not reflect the diversity of Florida's population. Minority populations, African-Americans in particular, have been found to have lower rates of mitigation adaption. These populations also tend on average to have lower household incomes and are therefore more price sensitive to potential rate increases caused by a removal of the surcharge system. It follows that lower income households would also have a decreasing marginal propensity to save which implies a decreasing level of support for a catastrophic type savings account. Our analysis shows that decreasing levels of income are negatively related to support for Catastrophic Savings.

\section{Discussion}

The focus of the preceding was an empirical analysis that allowed us to test several hypothesis related to issues facing policy makers in the area of Financing Hurricane Risk mitigation in the state of Florida. Our findings suggest that homeowners in higher risk areas associate of removal of the state's subsidized hurricane property insurance with higher premiums. Therefore Policymakers must find a way to address these constituents who may or may not have the means to afford such rate increases. We recommend that policymakers adopt the usage of an insurance credit for low income households in higher risk areas. Kunreuther and Michel-Kerjan (2009) outlines a similar policy that would establish a voucher type system for low-income households in high-hazard areas that could assist with pre and post disaster situations. Based on our findings, we additionally suggest that policymakers adopt catastrophic savings accounts as a means to address the issue of affordability, with the establish- 
ment of an initial endowment fund for those lower income households residing in high-hazard zones. Households who can afford rate increases could also benefit from these savings accounts via a system of tax credits.

In order to address the solvency issues in the National Flood Insurance program, our results suggest that current flood policy holders in the state of Florida are supportive of longer term contracts. However we note that further research is needed in order to establish an optimal contract period for homeowners and policymakers. While our findings represent Florida households and may not be representative of other states, further research could represent an informative first measure in reforming the NFIP. Comprehensive understanding of the public's perceptions can improve policy reform measures that are vital to the continued functioning of the financing of natural disaster mitigation. 


\section{BIBLIOGRAPHY}

Agresti, A. (2010). Analysis of ordinal categorical data, volume 656. John Wiley \& Sons.

Bagstad, K. J., Stapleton, K., and D'Agostino, J. R. (2007). Taxes, subsidies, and insurance as drivers of united states coastal development. Ecological Economics, $63(2): 285-298$.

Brant, R. (1990). Assessing proportionality in the proportional odds model for ordinal logistic regression. Biometrics, 46(4):1171-1178.

Capuano, A. W., Dawson, J. D., and Gray, G. C. (2007). Maximizing power in seroepidemiological studies through the use of the proportional odds model. Influenza and other respiratory viruses, 1(3):87-93.

Chapman, R. G. and Staelin, R. (1982). Exploiting rank ordered choice set data within the stochastic utility model. Journal of Marketing Research, 19(3):pp. $288-301$.

Chatterjee, C. and Mozumder, P. (2014). Understanding household preference for information regarding hurricane risk mitigation status: Evidence from survey responses. Risk Analysis, 34(6).

Christensen, R. H. B. (2011). Analysis of ordinal data with cumulative link models - estimation with the ordinal package. R-package version 2011.09-13.

Christensen, R. H. B. (2013). ordinal - regression models for ordinal data. R package version 2013.9-30 http://www.cran.r-project.org/package=ordinal/.

Cole, C. R., Macpherson, D. A., Maroney, P. F., McCullough, K. A., Newman Jr, J. W. J., and Nyce, C. (2011). The use of postloss financing of catastrophic risk. Risk Management and Insurance Review, 14(2):265-298.

Davenport, C. (2014). Senate passes bill to delay spike in flood insurance rates. New York Times.

FEMA (2014). Flood insurance reform act of 2012. http://www.fema.gov/floodinsurance-reform-act-2012. 
Fernandez, R. and Rodrik, D. (1991). Resistance to reform: Status quo bias in the presence of individual-specific uncertainty. The American economic review, 81(5):1146-1155.

Frewer, L. (1999). Risk perception, social trust, and public participation in strategic decision making: Implications for emerging technologies. Ambio, pages 569-574.

Ge, Y., Peacock, W. G., and Lindell, M. K. (2011). Florida households' expected responses to hurricane hazard mitigation incentives. Risk analysis, 31(10):16761691.

Grace, M. F. and Klein, R. W. (2009). The perfect storm: Hurricanes, insurance, and regulation. Risk Management and Insurance Review, 12(1):81-124.

Greene, W. H. and Hensher, D. A. (2010). Modeling ordered choices: A primer. Cambridge University Press.

Hahn, E. D. and Soyer, R. (2005). Probit and logit models: Differences in the multivariate realm. Submitted to The Journal of the Royal Statistical Society, Series B.

Harrell, F. E. (2001). Regression modeling strategies: with applications to linear models, logistic regression, and survival analysis. Springer.

Harrell, F. E. (2013a). Hmisc: Harrell Miscellaneous. R package version 3.12-2.

Harrell, F. E. (2013b). rms: Regression Modeling Strategies. R package version 4.1-0.

Harrell, F. E., Margolis, P. A., Gove, S., Mason, K. E., Mulholland, E. K., Lehmann, D., Muhe, L., Gatchalian, S., and Eichenwald, H. F. (1998). Development of a clinical prediction model for an ordinal outcome: the world health organization multicentre study of clinical signs and etiological agents of pneumonia, sepsis and meningitis in young infants. Statistics in medicine, 17(8):909-944.

Harrington, J. (2013). Premiums rising for national flood program, though florida pales in payouts. Tampa Bay Times.

Hart, P. S. and Nisbet, E. C. (2011). Boomerang effects in science communication: How motivated reasoning and identity cues amplify opinion polarization about 
climate mitigation policies. Communication Research.

Hornstein, D. T. (2013). The balkanization of cat property insurance: Financing and fragmentation in storm risks. RUTGERS JL \& PUB. POL'Y, 11:1.

Hosmer Jr, D. W. and Lemeshow, S. (2004). Applied logistic regression. John Wiley \& Sons.

Howe, P. D. (2011). Hurricane preparedness as anticipatory adaptation: A case study of community businesses. Global Environmental Change, 21(2):711-720.

Jaccard, J. and Wan, C. K. (1996). LISREL approaches to interaction effects in multiple regression. Number 114. Sage.

Kern, B. H. (2008). Florida extends 1\% hurricane surcharge until 2014.

Kunreuther, H. and Michel-Kerjan, E. O. (2009). At war with the weather: Managing large-scale risks in a new era of catastrophes. The MIT Press.

Lazo, J., Waldman, D., Morrow, B., and Thacher, J. (2010). Household evacuation decision making and the benefits of improved hurricane forecasting: developing a framework for assessment. Weather and Forecasting, 25:207.

Leiserowitz, A. (2006). Climate change risk perception and policy preferences: the role of affect, imagery, and values. Climatic change, 77(1-2):45-72.

Long, J. S. (1997). Regression models for categorical and limited dependent variables, volume 7. Sage.

McCullagh, P. (1980). Regression models for ordinal data. Journal of the Royal Statistical Society, Series B, 42(2):109-142.

McKelvey, R. D. and Zavoina, W. (1975). A statistical model for the analysis of ordinal level dependent variables. The Journal of Mathematical Sociology, 4(1):103120 .

Michel-Kerjan, E. O. and Kousky, C. (2010). Come rain or shine: Evidence on flood insurance purchases in florida. The Journal of Risk and Insurance, 77(2):pp. 369397. 
Mozumder, P., Flugman, E., and Randhir, T. (2011). Adaptation behavior in the face of global climate change: Survey responses from experts and decision makers serving the florida keys. Ocean \& Coastal Management, 54(1):37-44.

Nelson, T. E. and Kinder, D. R. (1996). Issue frames and group-centrism in american public opinion. The Journal of Politics, 58(04):1055-1078.

Paetzel, F., Sausgruber, R., and Traub, S. (2012). Social preferences and voting on reform-an experimental study. Available at SSRN 2066455.

Peacock, W. G. (2003). Hurricane mitigation status and factors influencing mitigation status among florida's single-family homeowners. Natural Hazards Review, 4(3):149-158.

Peacock, W. G., Brody, S. D., and Highfield, W. (2005). Hurricane risk perceptions among florida's single family homeowners. Landscape and Urban Planning, 73(2):120-135.

Peel, M. J., Goode, M. M., and Moutinho, L. A. (1998). Estimating consumer satisfaction: Ols versus ordered probability models. International Journal of Commerce and Management, 8(2):75-93.

Peterson, B. and Harrell Jr, F. E. (1990). Partial proportional odds models for ordinal response variables. Applied Statistics, pages 205-217.

Petrolia, D. R., Landry, C. E., and Coble, K. H. (2011). Risk preferences, risk perceptions, and demand for flood insurance. Under review. Available at SSRN: http://ssrn. com/abstract, 1843326.

Prater, C. S. and Lindell, M. K. (2000). Politics of hazard mitigation. Natural Hazards Review, 1(2):73-82.

Scott, S. C., Goldberg, M. S., and Mayo, N. E. (1997). Statistical assessment of ordinal outcomes in comparative studies. Journal of clinical epidemiology, $50(1): 45-55$.

Siegrist, M. and Cvetkovich, G. (2000). Perception of hazards: The role of social trust and knowledge. Risk analysis, 20(5):713-720. 
Sniderman, P. M., Tetlock, P. E., and Brody, R. A. (1993). Reasoning and choice: Explorations in political psychology. Cambridge University Press.

Stoutenborough, J. W., Sturgess, S. G., and Vedlitz, A. (2013). Knowledge, risk, and policy support: Public perceptions of nuclear power. Energy Policy, 62(0):176 $-184$.

Strömberg, U. (1996). Collapsing ordered outcome categories: A note of concern. American journal of epidemiology, 144(4):421-424.

Verchick, R. R. and Johnson, L. R. (2014). When retreat is the best option: Flood insurance after biggert-waters and other climate change puzzles.

Winship, C. and Mare, R. D. (1984). Regression models with ordinal variables. American Sociological Review, pages 512-525.

Yee, T. W. (2010). The VGAM package for categorical data analysis. Journal of Statistical Software, 32(10):1-34. 
APPENDICES 


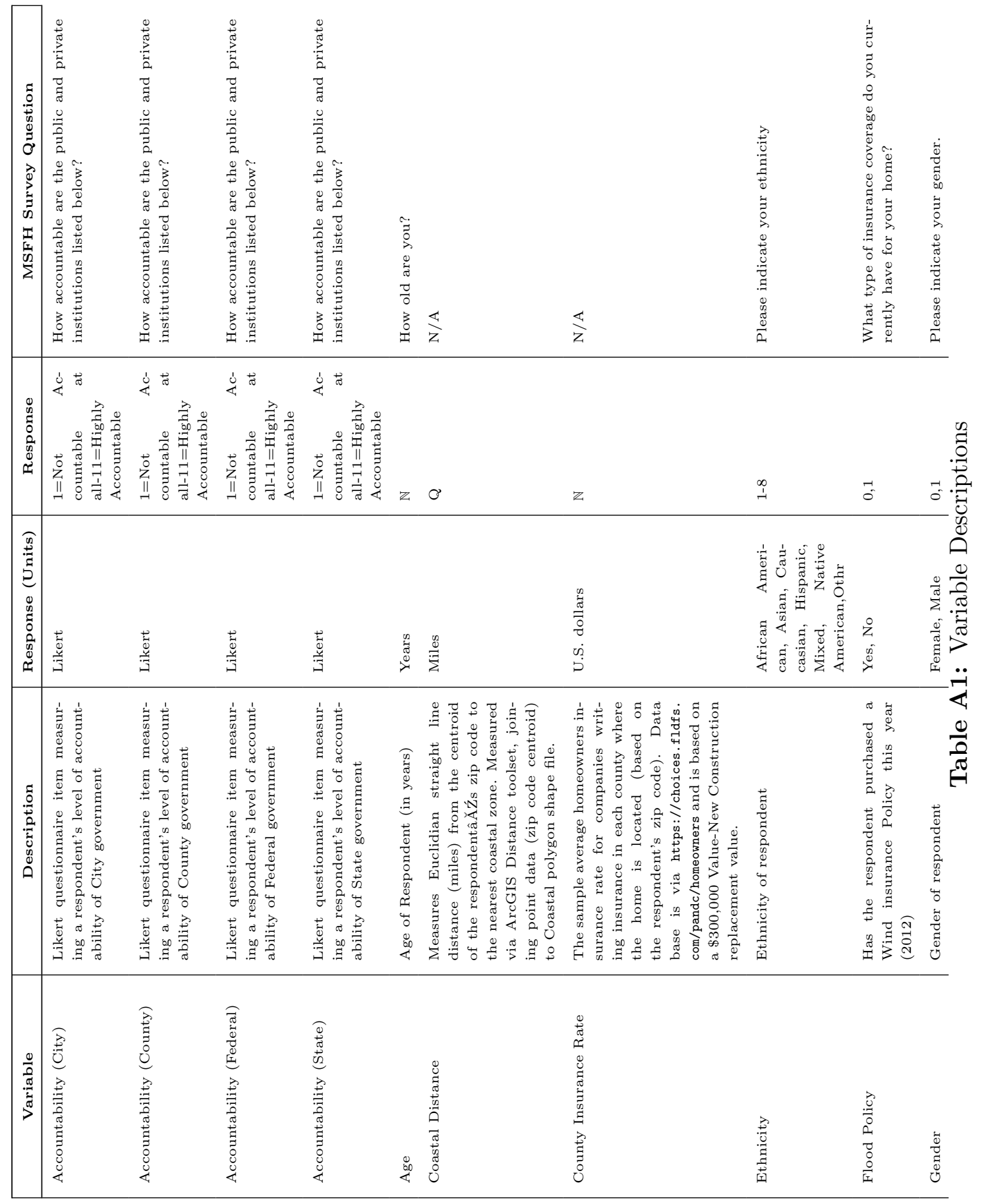




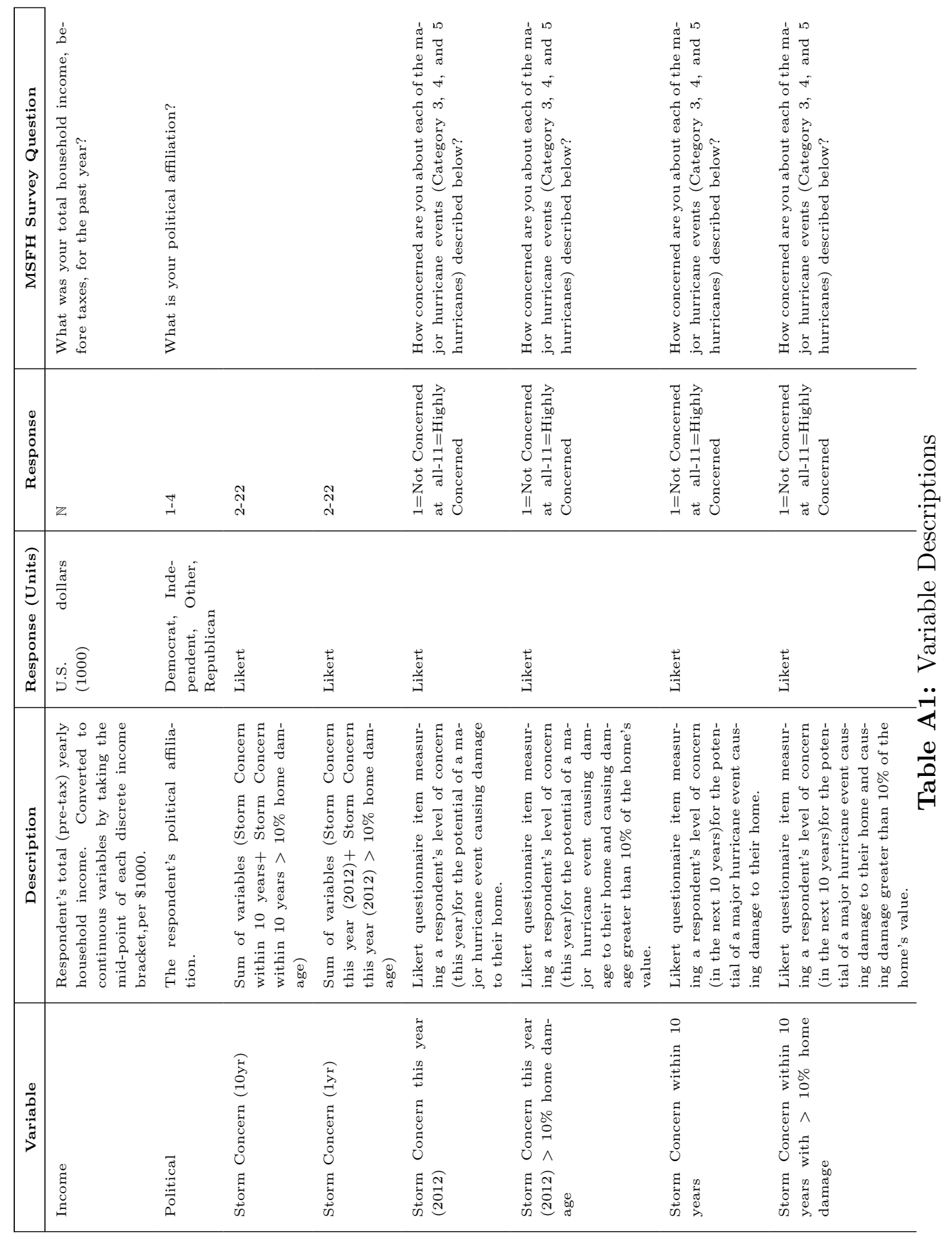




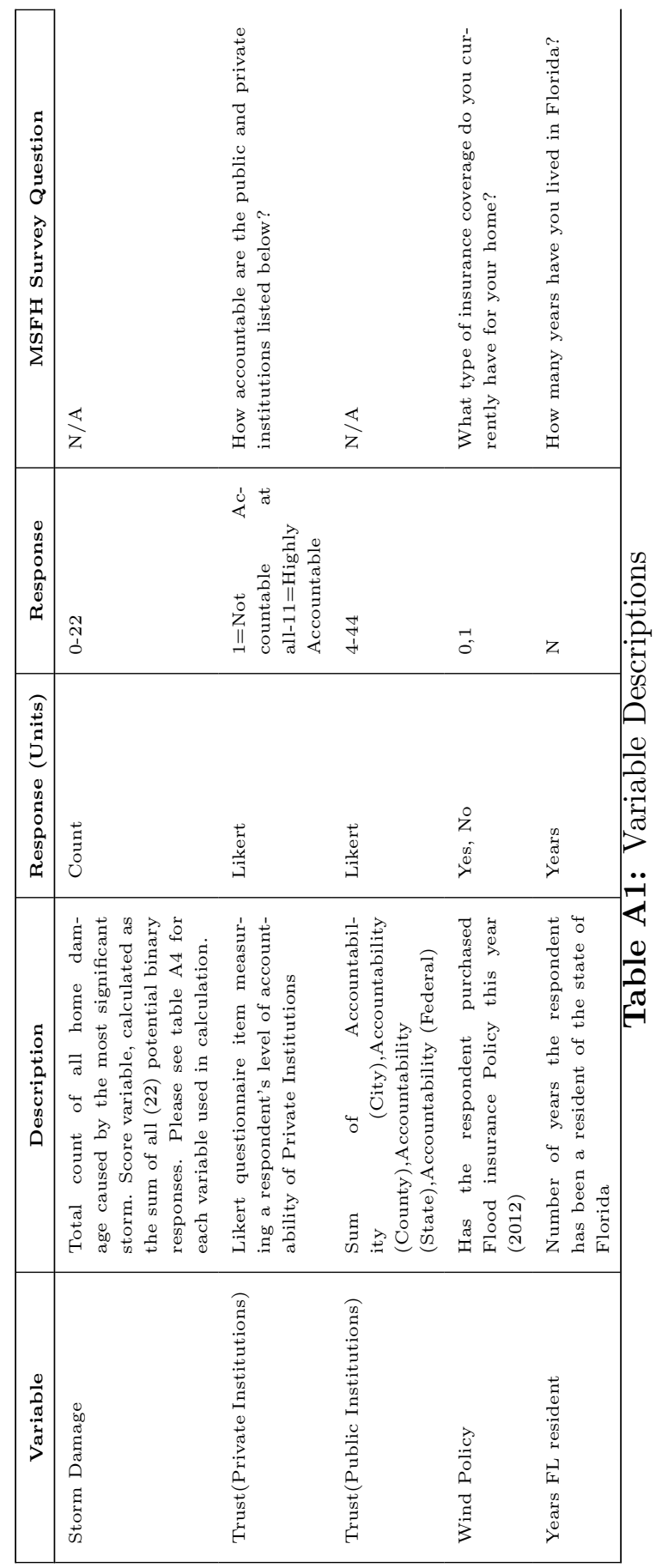


Table A2: Continuous variables.

\begin{tabular}{|c|c|c|c|c|c|c|}
\hline Variable & $\mathbf{n}$ & $\overline{\mathbf{x}}$ & s & Min & Max & \#NA \\
\hline Age & 1352 & 58.8 & 11.6 & 27.0 & 91.0 & 42 \\
\hline Accountability City government & 1344 & 6.2 & 2.9 & 1.0 & 11.0 & 50 \\
\hline Accountability County government & 1354 & 6.3 & 2.9 & 1.0 & 11.0 & 40 \\
\hline Accountability State government & 1355 & 6.5 & 3.0 & 1.0 & 11.0 & 39 \\
\hline Accountability Federal government & 1353 & 6.3 & 3.1 & 1.0 & 11.0 & 41 \\
\hline Accountability Private Insurance firms & 1354 & 7.1 & 3.4 & 1.0 & 11.0 & 40 \\
\hline Coastal Distance & 1321 & 3.5 & 5.8 & 0.0 & 44.9 & 73 \\
\hline County Insurance Rate & 1264 & 3.8 & 1.6 & 1.2 & 7.2 & 130 \\
\hline Income & 1272 & 89.1 & 52.6 & 20.0 & 250.0 & 122 \\
\hline Storm Damage & 1394 & 1.8 & 2.5 & 0.0 & 17.0 & 0 \\
\hline Storm Concern this year (2012) & 1380 & 6.4 & 2.8 & 1.0 & 11.0 & 14 \\
\hline Storm Concern this year $(2012)>10 \%$ home damage & 1380 & 6.1 & 3.0 & 1.0 & 11.0 & 14 \\
\hline Storm Concern within 10 years & 1380 & 7.2 & 2.9 & 1.0 & 11.0 & 14 \\
\hline Storm Concern within 10 years with $>10 \%$ home damage & 1382 & 7.0 & 3.1 & 1.0 & 11.0 & 12 \\
\hline Years FL resident & 1372 & 29.6 & 16.5 & 1.0 & 79.0 & 22 \\
\hline
\end{tabular}

Table A3: Discrete variables

\begin{tabular}{ll|rr} 
Variable & Levels & $\mathbf{n}$ & $\%$ \\
\hline Ethnicity & Ccsn & 1114 & 79.9 \\
& AA & 65 & 4.7 \\
& Hspn & 98 & 7.0 \\
& Othr & 73 & 5.2 \\
& missing & 44 & 3.2 \\
\hline & all & 1394 & 100.0 \\
\hline \hline Gender & Female & 588 & 42.2 \\
& Male & 786 & 56.4 \\
& missing & 20 & 1.4 \\
\hline \hline Political Party & all & 1394 & 100.0 \\
& Rpbl & 475 & 34.1 \\
& Dmcrt & 367 & 26.3 \\
& Indp & 201 & 14.4 \\
& Othr & 250 & 17.9 \\
& missing & 101 & 7.2 \\
\hline & all & 1394 & 100.0 \\
\hline
\end{tabular}


Table A4: MSFH Survey: Storm Damage variable, specific components

\begin{tabular}{|c|c|c|c|}
\hline Variable & Levels & $\mathbf{n}$ & $\%$ \\
\hline \multirow[t]{3}{*}{ Roof cover failure } & 0 & 979 & 70.2 \\
\hline & 1 & 415 & 29.8 \\
\hline & all & 1394 & 100.0 \\
\hline \multirow[t]{3}{*}{ Roof deck failure (sheathing) } & 0 & 1311 & 94.0 \\
\hline & 1 & 83 & 6.0 \\
\hline & all & 1394 & 100.0 \\
\hline \multirow[t]{3}{*}{ Roof-to-wall connection failure } & 0 & 1367 & 98.1 \\
\hline & 1 & 27 & 1.9 \\
\hline & all & 1394 & 100.0 \\
\hline \multirow[t]{3}{*}{ Wall covering/cladding failure } & 0 & 1369 & 98.2 \\
\hline & 1 & 25 & 1.8 \\
\hline & all & 1394 & 100.0 \\
\hline \multirow[t]{3}{*}{ Accessory structure failure (screen enclosures, porches, carports) } & 0 & 1164 & 83.5 \\
\hline & 1 & 230 & 16.5 \\
\hline & all & 1394 & 100.0 \\
\hline \multirow[t]{3}{*}{ Damage from wind/wind-borne debris } & 0 & 1171 & 84.0 \\
\hline & 1 & 223 & 16.0 \\
\hline & all & 1394 & 100.0 \\
\hline \multirow[t]{3}{*}{ Damage from wind-driven rainwater intrusion/penetration } & 0 & 1230 & 88.2 \\
\hline & 1 & 164 & 11.8 \\
\hline & all & 1394 & 100.0 \\
\hline \multirow[t]{3}{*}{ Damage from inland flooding } & 0 & 1379 & 98.9 \\
\hline & 1 & 15 & 1.1 \\
\hline & all & 1394 & 100.0 \\
\hline \multirow[t]{3}{*}{ Damage from storm surge } & 0 & 1363 & 97.8 \\
\hline & 1 & 31 & 2.2 \\
\hline & all & 1394 & 100.0 \\
\hline \multirow[t]{3}{*}{ Damage from fallen trees/tree limbs } & 0 & 1135 & 81.4 \\
\hline & 1 & 259 & 18.6 \\
\hline & all & 1394 & 100.0 \\
\hline \multirow[t]{3}{*}{ Damage from broken/dislodged exterior equipment } & 0 & 1332 & 95.5 \\
\hline & 1 & 62 & 4.5 \\
\hline & all & 1394 & 100.0 \\
\hline \multirow[t]{3}{*}{ Broken windows, entry doors, sliding glass doors, skylights } & 0 & 1297 & 93.0 \\
\hline & 1 & 97 & 7.0 \\
\hline & all & 1394 & 100.0 \\
\hline \multirow[t]{3}{*}{ Garage door failure } & 0 & 1365 & 97.9 \\
\hline & 1 & 29 & 2.1 \\
\hline & all & 1394 & 100.0 \\
\hline \multirow[t]{3}{*}{ Soffit/vent failure (gable-end, ridge, roof, soffit, turbine vents) } & 0 & 1298 & 93.1 \\
\hline & 1 & 96 & 6.9 \\
\hline & all & 1394 & 100.0 \\
\hline \multirow[t]{3}{*}{ Gutter/downspout failure } & 0 & 1321 & 94.8 \\
\hline & 1 & 73 & 5.2 \\
\hline & all & 1394 & 100.0 \\
\hline Interior contents/furnishings damage & 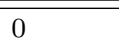 & 1295 & 92.9 \\
\hline
\end{tabular}




\begin{tabular}{ll|rr} 
& 1 & 99 & 7.1 \\
\hline \hline Interior finishes damage (ceilings, walls, flooring) & all & 1394 & 100.0 \\
\hline & 0 & 1221 & 87.6 \\
\hline Ceiling collapse (saturated insulation) & 1 & 173 & 12.4 \\
\hline & all & 1394 & 100.0 \\
\hline \hline Utilities damage (electrical, mechanical, plumbing) & 0 & 1332 & 95.5 \\
& 1 & 62 & 4.5 \\
\hline & all & 1394 & 100.0 \\
\hline \hline Mold growth & 0 & 1315 & 94.3 \\
& 1 & 79 & 5.7 \\
\hline \hline OTHER & all & 1394 & 100.0 \\
\hline & 0 & 1318 & 94.5 \\
\hline & 1 & 76 & 5.5 \\
\hline
\end{tabular}


Table A5: Policy Question response rate (Dependent Variable(s) for ORM)

\begin{tabular}{|c|c|c|c|}
\hline Variable & Levels & $\mathbf{n}$ & $\%$ \\
\hline \multirow[t]{7}{*}{ Surcharge } & 1 & 236 & 16.9 \\
\hline & 2 & 133 & 9.5 \\
\hline & 3 & 425 & 30.5 \\
\hline & 4 & 299 & 21.4 \\
\hline & 5 & 276 & 19.8 \\
\hline & missing & 25 & 1.8 \\
\hline & all & 1394 & 100.0 \\
\hline \multirow[t]{7}{*}{ Flood (5 year) } & 1 & 234 & 16.8 \\
\hline & 2 & 95 & 6.8 \\
\hline & 3 & 406 & 29.1 \\
\hline & 4 & 263 & 18.9 \\
\hline & 5 & 335 & 24.0 \\
\hline & missing & 61 & 4.4 \\
\hline & all & 1394 & 100.0 \\
\hline \multirow[t]{7}{*}{ Flood(30 year) } & 1 & 401 & 28.8 \\
\hline & 2 & 150 & 10.8 \\
\hline & 3 & 369 & 26.5 \\
\hline & 4 & 173 & 12.4 \\
\hline & 5 & 222 & 15.9 \\
\hline & missing & 79 & 5.7 \\
\hline & all & 1394 & 100.0 \\
\hline \multirow[t]{7}{*}{ All-Hazards insurance } & 1 & 68 & 4.9 \\
\hline & 2 & 40 & 2.9 \\
\hline & 3 & 247 & 17.7 \\
\hline & 4 & 372 & 26.7 \\
\hline & 5 & 641 & 46.0 \\
\hline & missing & 26 & 1.9 \\
\hline & all & 1394 & 100.0 \\
\hline \multirow[t]{7}{*}{ Catastrophe savings } & 1 & 133 & 9.5 \\
\hline & 2 & 69 & 5.0 \\
\hline & 3 & 309 & 22.2 \\
\hline & 4 & 348 & 25.0 \\
\hline & 5 & 510 & 36.6 \\
\hline & missing & 25 & 1.8 \\
\hline & all & 1394 & 100.0 \\
\hline
\end{tabular}




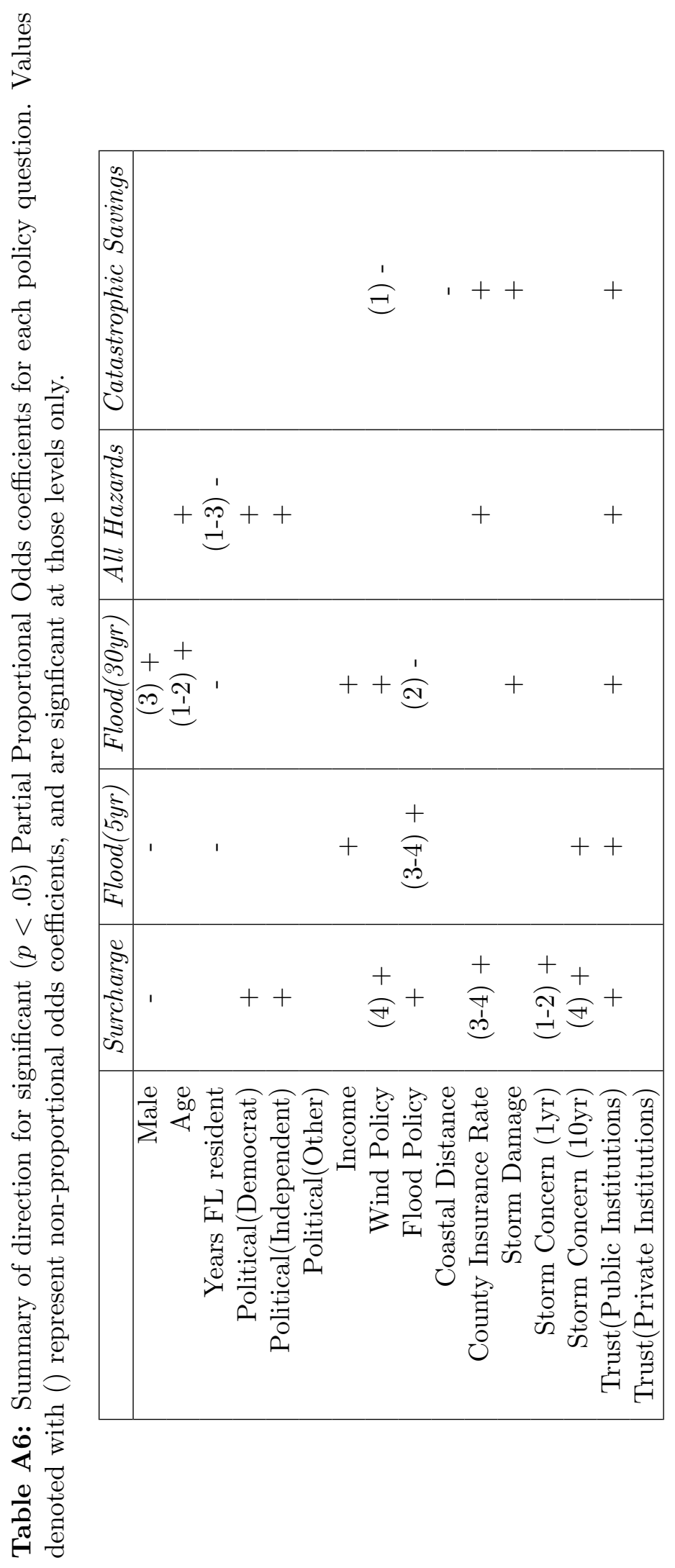


Table A7: Partial Proportional Odds Model predicting Florida Single Family Homeowners preference for Surcharge.

\begin{tabular}{|c|c|c|}
\hline & Estimate & Odds \\
\hline Male & $-0.368^{b}$ & 0.692 \\
\hline Age & 0.008 & 1.008 \\
\hline Years FL resident & 0 & 1 \\
\hline Political(Democrat) & $0.258^{\mathrm{d}}$ & 1.294 \\
\hline Political(Independent) & $0.448^{\mathrm{c}}$ & 1.565 \\
\hline Political(Other) & 0.167 & 1.182 \\
\hline Income & -0.001 & 0.999 \\
\hline Wind Policy*:1 & 0.081 & 1.084 \\
\hline Wind Policy*:2 & -0.078 & 0.925 \\
\hline Wind Policy*:3 & 0.156 & 1.168 \\
\hline Wind Policy*:4 & $0.455^{\mathrm{c}}$ & 1.576 \\
\hline Flood Policy & $0.376^{\mathrm{b}}$ & 1.457 \\
\hline Coastal Distance & -0.017 & 0.983 \\
\hline County Insurance Rate*:1 & -0.04 & 0.961 \\
\hline County Insurance Rate*:2 & -0.025 & 0.975 \\
\hline County Insurance Rate*:3 & $0.088^{\mathrm{d}}$ & 1.092 \\
\hline County Insurance Rate*:4 & $0.117^{\mathrm{c}}$ & 1.124 \\
\hline Storm Damage & 0.027 & 1.028 \\
\hline Storm Concern $(1 \mathrm{yr})^{*}: 1$ & $0.072^{\mathrm{c}}$ & 1.075 \\
\hline Storm Concern $(1 \mathrm{yr})^{*}: 2$ & $0.085^{\mathrm{a}}$ & 1.088 \\
\hline Storm Concern $(1 \mathrm{yr})^{*}: 3$ & 0.036 & 1.036 \\
\hline Storm Concern $(1 \mathrm{yr})^{*}: 4$ & -0.01 & 0.99 \\
\hline Storm Concern $(10 y r)^{*}: 1$ & -0.034 & 0.967 \\
\hline Storm Concern $(10 y r)^{*}: 2$ & -0.02 & 0.98 \\
\hline Storm Concern $(10 y r)^{*}: 3$ & 0.024 & 1.024 \\
\hline Storm Concern $(10 \mathrm{yr})^{*}: 4$ & $0.051^{\mathrm{c}}$ & 1.052 \\
\hline Trust(Public Institutions) ${ }^{*}: 1$ & $0.074^{\mathrm{a}}$ & 1.077 \\
\hline Trust(Public Institutions) ${ }^{*}: 2$ & $0.067^{\mathrm{a}}$ & 1.069 \\
\hline Trust(Public Institutions) ${ }^{*}: 3$ & $0.047^{\mathrm{a}}$ & 1.048 \\
\hline Trust(Public Institutions) ${ }^{*}: 4$ & $0.045^{\mathrm{a}}$ & 1.047 \\
\hline Trust(Private Institutions) & -0.023 & 0.978 \\
\hline $\log \mathrm{L}$ & -1394.395 & \\
\hline $\operatorname{LR} \chi_{(31)}^{2}$ & 212.884 & \\
\hline AIC & 2858.79 & \\
\hline
\end{tabular}

\footnotetext{
${ }^{\mathrm{a}} \mathrm{p}<.001 ;^{\mathrm{b}} \mathrm{p}<.01 ;^{\mathrm{c}} \mathrm{p}<.05 ;^{*}$ Non-Proportional Odds Coefficients
} 
Table A8: Partial Proportional Odds Model predicting Florida Single Family Homeowners preference for Flood(5yr).

\begin{tabular}{|c|c|c|}
\hline & Estimate & Odds \\
\hline Male & $-0.283^{\mathrm{c}}$ & 0.753 \\
\hline Age & 0.003 & 1.003 \\
\hline Years FL resident & $-0.008^{\mathrm{c}}$ & 0.992 \\
\hline Political(Democrat) & 0.043 & 1.044 \\
\hline Political(Independent) & 0.098 & 1.103 \\
\hline Political(Other) & -0.242 & 0.785 \\
\hline Income & $0.005^{\mathrm{a}}$ & 1.005 \\
\hline Wind Policy & 0.17 & 1.186 \\
\hline Flood Policy*:1 & 0.073 & 1.076 \\
\hline Flood Policy*:2 & 0.216 & 1.241 \\
\hline Flood Policy*:3 & $0.339^{\mathrm{c}}$ & 1.403 \\
\hline Flood Policy*:4 & $0.6^{\mathrm{a}}$ & 1.822 \\
\hline Coastal Distance & 0.001 & 1.001 \\
\hline County Insurance Rate & 0.001 & 1.001 \\
\hline Storm Damage & 0.015 & 1.015 \\
\hline Storm Concern (1yr) & 0 & 1 \\
\hline Storm Concern (10yr) & $0.039^{\mathrm{c}}$ & 1.039 \\
\hline Trust(Public Institutions) & $0.032^{\mathrm{a}}$ & 1.033 \\
\hline Trust(Private Institutions)*:1 & -0.035 & 0.965 \\
\hline Trust(Private Institutions)*:2 & -0.024 & 0.976 \\
\hline Trust(Private Institutions) ${ }^{*}: 3$ & -0.03 & 0.97 \\
\hline Trust(Private Institutions) ${ }^{*}: 4$ & 0.004 & 1.004 \\
\hline $\log \mathrm{L}$ & -1429.465 & \\
\hline $\operatorname{LR} \chi_{(22)}^{2}$ & 99.54 & \\
\hline AIC & 2910.931 & \\
\hline
\end{tabular}

${ }^{\mathrm{a}} \mathrm{p}<.001 ;^{\mathrm{b}} \mathrm{p}<.01 ;^{\mathrm{c}} \mathrm{p}<.05 ;^{*}$ Non-Proportional Odds Coefficients 
Table A9: Partial Proportional Odds Model predicting Florida Single Family Homeowners preference for Flood(30yr).

\begin{tabular}{|c|c|c|}
\hline & Estimate & Odds \\
\hline Male*:1 & 0.105 & 1.111 \\
\hline Male*:2 & 0.039 & 1.04 \\
\hline Male*:3 & $0.373^{\mathrm{c}}$ & 1.452 \\
\hline Male*:4 & 0.151 & 1.164 \\
\hline $\operatorname{Age}^{*}: 1$ & $-0.021^{b}$ & 0.979 \\
\hline Age* $: 2^{2}$ & $-0.013^{\mathrm{c}}$ & 0.987 \\
\hline Age* $^{*}: 3$ & -0.01 & 0.99 \\
\hline Age* $^{*} 4$ & -0.007 & 0.993 \\
\hline Years FL resident & $-0.008^{\mathrm{c}}$ & 0.992 \\
\hline Political(Democrat) & 0.034 & 1.035 \\
\hline Political(Independent) & 0.133 & 1.142 \\
\hline Political(Other) & -0.135 & 0.874 \\
\hline Income & $0.003^{\mathrm{c}}$ & 1.003 \\
\hline Wind Policy & $0.31^{\mathrm{c}}$ & 1.363 \\
\hline Flood Policy*:1 & -0.239 & 0.788 \\
\hline Flood Policy*:2 & $-0.288^{\mathrm{c}}$ & 0.75 \\
\hline Flood Policy*:3 & -0.13 & 0.878 \\
\hline Flood Policy*:4 & 0.239 & 1.27 \\
\hline Coastal Distance & 0.004 & 1.004 \\
\hline County Insurance Rate & -0.057 & 0.944 \\
\hline Storm Damage & $0.044^{\mathrm{d}}$ & 1.045 \\
\hline Storm Concern (1yr) & 0.004 & 1.004 \\
\hline Storm Concern (10yr) & 0.022 & 1.022 \\
\hline Trust(Public Institutions) & $0.022^{\mathrm{a}}$ & 1.022 \\
\hline Trust(Private Institutions)*:1 & -0.021 & 0.98 \\
\hline Trust(Private Institutions) ${ }^{*}: 2$ & -0.008 & 0.992 \\
\hline Trust(Private Institutions) ${ }^{*}: 3$ & -0.03 & 0.97 \\
\hline Trust(Private Institutions) ${ }^{*}: 4$ & 0.017 & 1.017 \\
\hline $\log \mathrm{L}$ & -1446.826 & \\
\hline $\operatorname{LR} \chi_{(28)}^{2}$ & 80.598 & \\
\hline AIC & 2957.652 & \\
\hline
\end{tabular}


Table A10: Partial Proportional Odds Model predicting Florida Single Family Homeowners preference for All Hazards.

\begin{tabular}{|c|c|c|}
\hline & Estimate & Odds \\
\hline Male*:1 & -0.555 & 0.574 \\
\hline Male*:2 & -0.188 & 0.828 \\
\hline Male*:3 & -0.124 & 0.883 \\
\hline Male*:4 & -0.002 & 0.998 \\
\hline Age*:1 & -0.013 & 0.988 \\
\hline $\operatorname{Age}^{*}: 2$ & -0.01 & 0.99 \\
\hline Age* $^{*} 3$ & 0.005 & 1.005 \\
\hline Age $^{*}: 4$ & $0.013^{\mathrm{c}}$ & 1.013 \\
\hline Years FL resident*:1 & $-0.015^{\mathrm{d}}$ & 0.985 \\
\hline Years FL resident ${ }^{*} 2$ & $-0.018^{\mathrm{b}}$ & 0.982 \\
\hline Years FL resident*:3 & $-0.011^{\mathrm{c}}$ & 0.989 \\
\hline Years FL resident*:4 & -0.006 & 0.994 \\
\hline Political(Democrat) & $0.293^{\mathrm{d}}$ & 1.34 \\
\hline Political(Independent) & $0.43^{\mathrm{c}}$ & 1.538 \\
\hline Political(Other) & -0.081 & 0.923 \\
\hline Income & 0 & 1 \\
\hline Wind Policy & -0.019 & 0.981 \\
\hline Flood Policy & 0.153 & 1.166 \\
\hline Coastal Distance*: 1 & 0.039 & 1.04 \\
\hline Coastal Distance* $: 2$ & 0.028 & 1.028 \\
\hline Coastal Distance*:3 & -0.016 & 0.984 \\
\hline Coastal Distance*:4 & -0.007 & 0.993 \\
\hline County Insurance Rate & $0.106^{\mathrm{c}}$ & 1.112 \\
\hline Storm Damage & -0.001 & 0.999 \\
\hline Storm Concern (1yr) & 0.02 & 1.02 \\
\hline Storm Concern (10yr) & 0.018 & 1.019 \\
\hline Trust(Public Institutions) & $0.014^{\mathrm{c}}$ & 1.014 \\
\hline Trust(Private Institutions) & -0.024 & 0.976 \\
\hline $\log \mathrm{L}$ & -1200.476 & \\
\hline $\mathrm{LR} \chi_{(28)}^{2}$ & 72.304 & \\
\hline AIC & 2464.951 & \\
\hline
\end{tabular}


Table A11: Partial Proportional Odds Model predicting Florida Single Family Homeowners preference for Catastrophic Savings.

\begin{tabular}{rll}
\hline & Estimate & Odds \\
Male & 0.067 & 1.069 \\
Age & -0.009 & 0.991 \\
Years FL resident & 0.002 & 1.002 \\
Political(Democrat) & 0.081 & 1.084 \\
Political(Independent) & 0.225 & 1.252 \\
Political(Other) & 0.168 & 1.183 \\
Income & $0.002^{\mathrm{c}}$ & 1.002 \\
Wind Policy*:1 & $-0.896^{\mathrm{b}}$ & 0.408 \\
Wind Policy*:2 & -0.161 & 0.852 \\
Wind Policy ${ }^{*}: 3$ & -0.103 & 0.902 \\
Wind Policy* ${ }^{*} 4$ & 0.165 & 1.179 \\
Flood Policy & -0.039 & 0.962 \\
Coastal Distance & $-0.026^{\mathrm{c}}$ & 0.975 \\
County Insurance Rate & $0.07^{\mathrm{d}}$ & 1.073 \\
Storm Damage & $0.051^{\mathrm{c}}$ & 1.052 \\
Storm Concern (1yr) & 0.03 & 1.03 \\
Storm Concern (10yr) & -0.003 & 0.997 \\
Trust(Public Institutions) & $0.019^{\mathrm{b}}$ & 1.02 \\
Trust(Private Institutions) & 0.006 & 1.006 \\
Log L & -1340.21 & \\
LR $\chi_{(19)}^{2}$ & 72.848 & \\
AIC & 2726.42 & \\
\hline
\end{tabular}

${ }^{\mathrm{a}} \mathrm{p}<.001 ;^{\mathrm{b}} \mathrm{p}<.01 ;^{\mathrm{c}} \mathrm{p}<.05 ;^{*}$ Non-Proportional Odds Coefficients 
Figure A1: Ordinality Assumption: Mean of individual covariates vs. levels of Surcharge response. The expected value of the predictor, under the assumption of proportional odds, for each Surcharge value is represented as a dotted line.
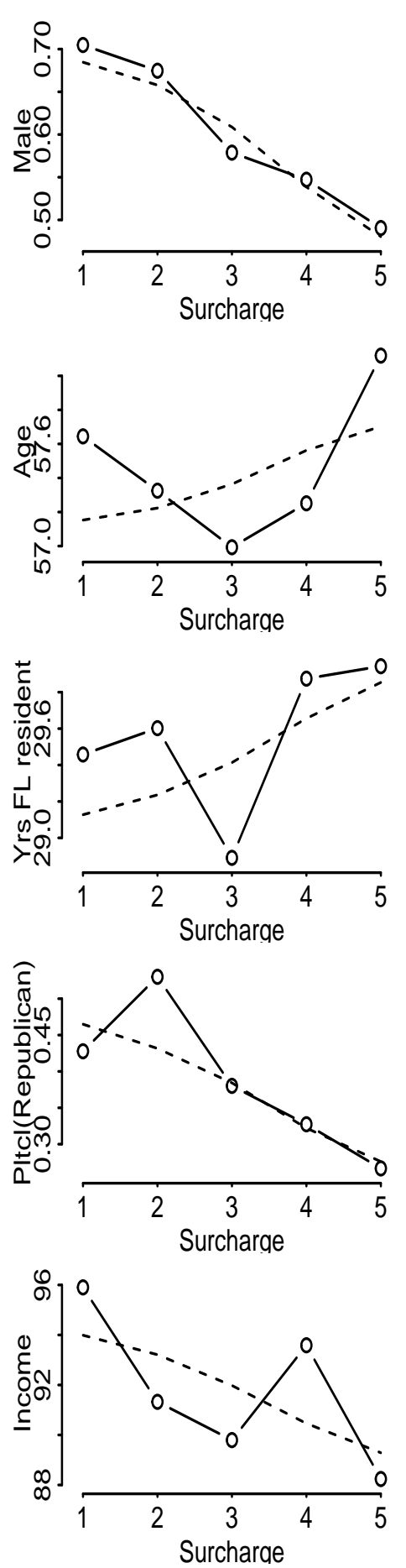
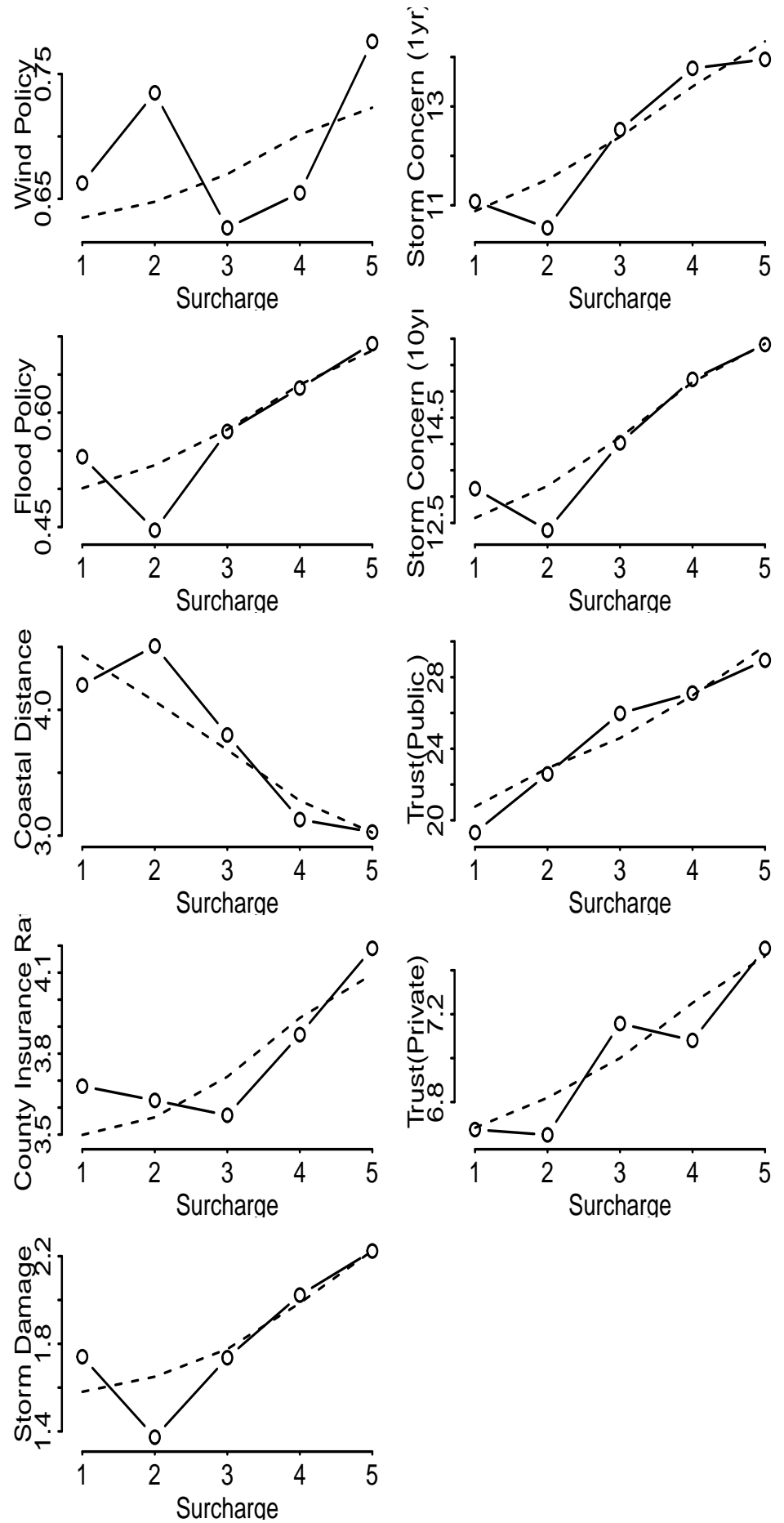
Figure A2: Ordinality Assumption: Mean of individual covariates vs. levels of Flood(5yr) response. The expected value of the predictor, under the assumption of proportional odds, for each Flood(5yr) value is represented as a dotted line.
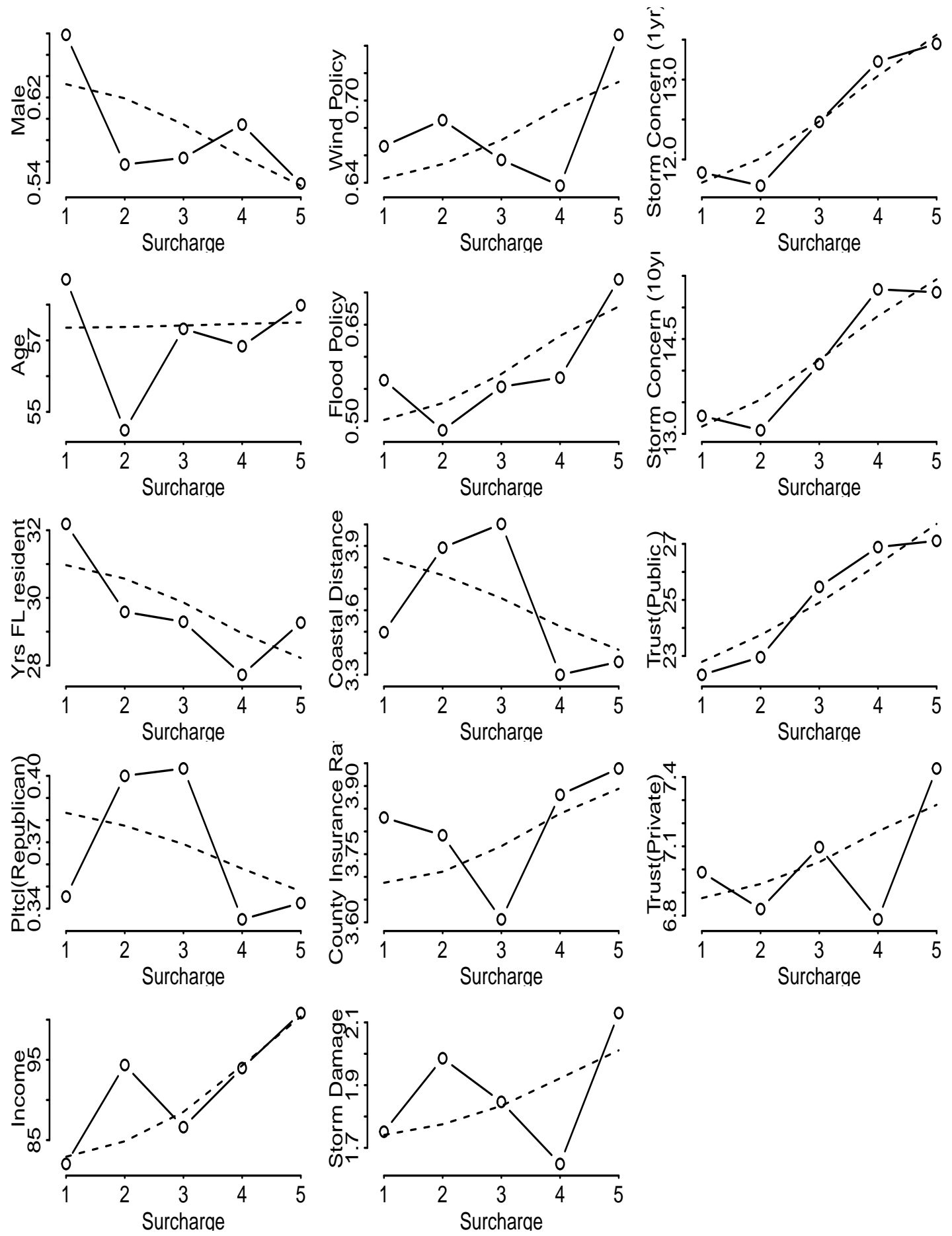
Figure A3: Ordinality Assumption: Mean of individual covariates vs. levels of Flood(30yr) response. The expected value of the predictor, under the assumption of proportional odds, for each Flood(30yr) value is represented as a dotted line.
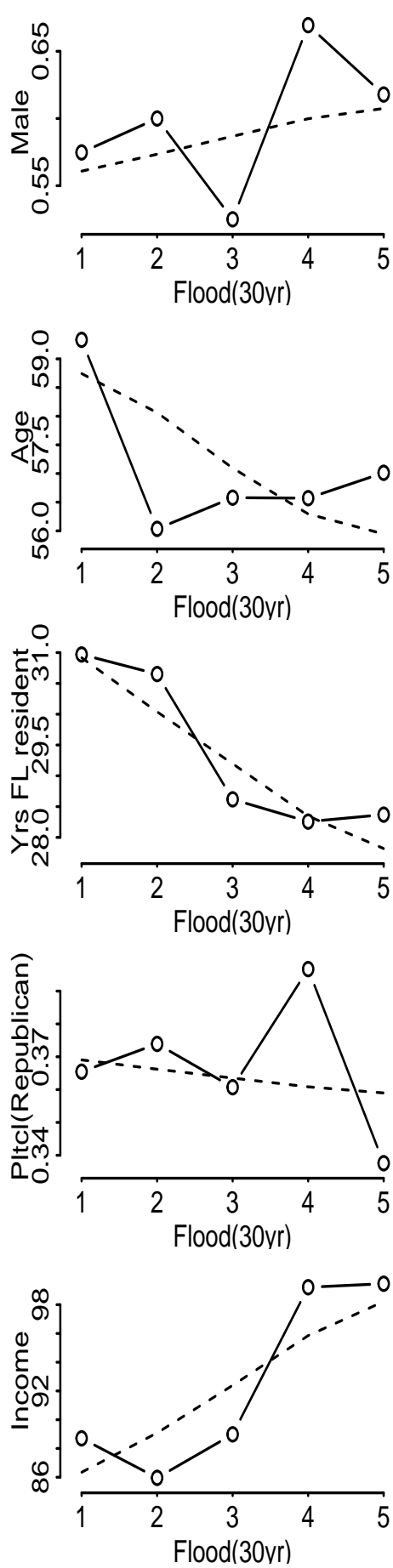
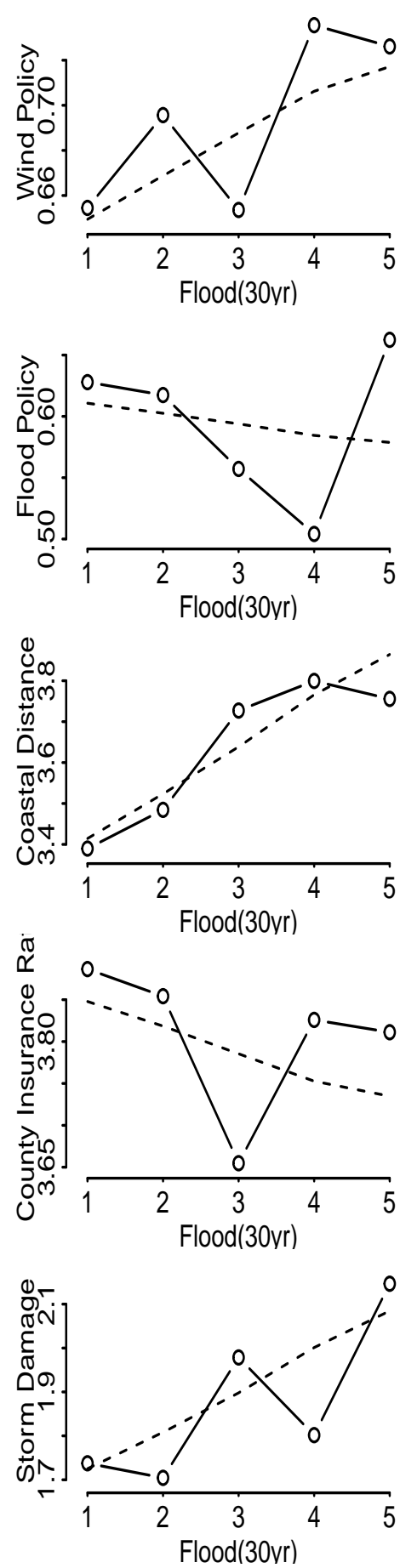
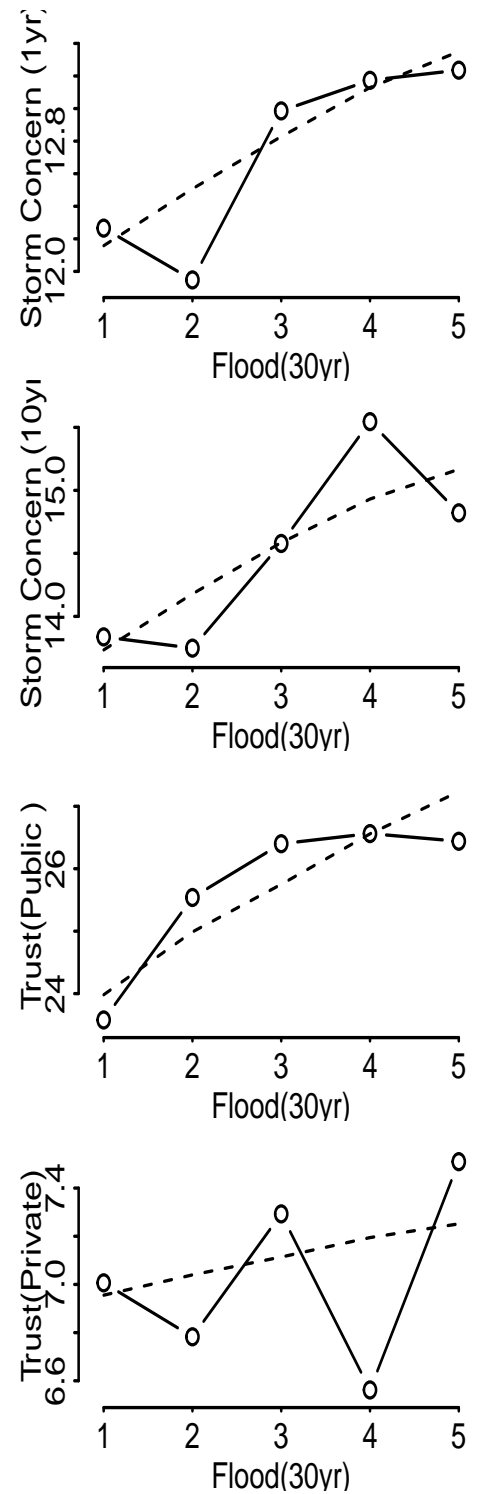

Flood(30vr) 
Figure A4: Ordinality Assumption: Mean of individual covariates vs. levels of All Hazards response. The expected value of the predictor, under the assumption of proportional odds, for each All Hazards value is represented as a dotted line.
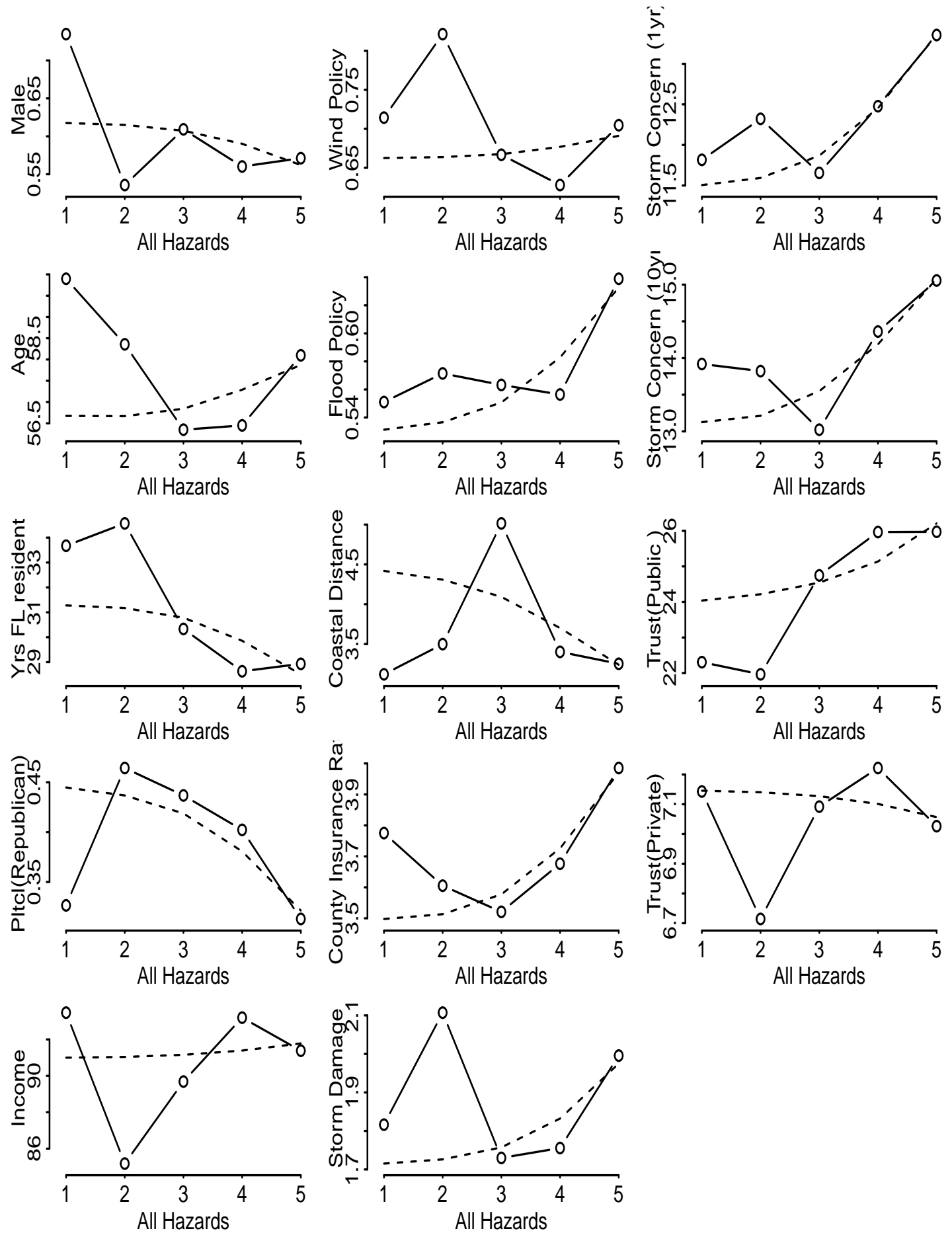
Figure A5: Ordinality Assumption: Mean of individual covariates vs. levels of Catastrophic Savings response. The expected value of the predictor, under the assumption of proportional odds, for each Catastrophic Savings value is represented as a dotted line.
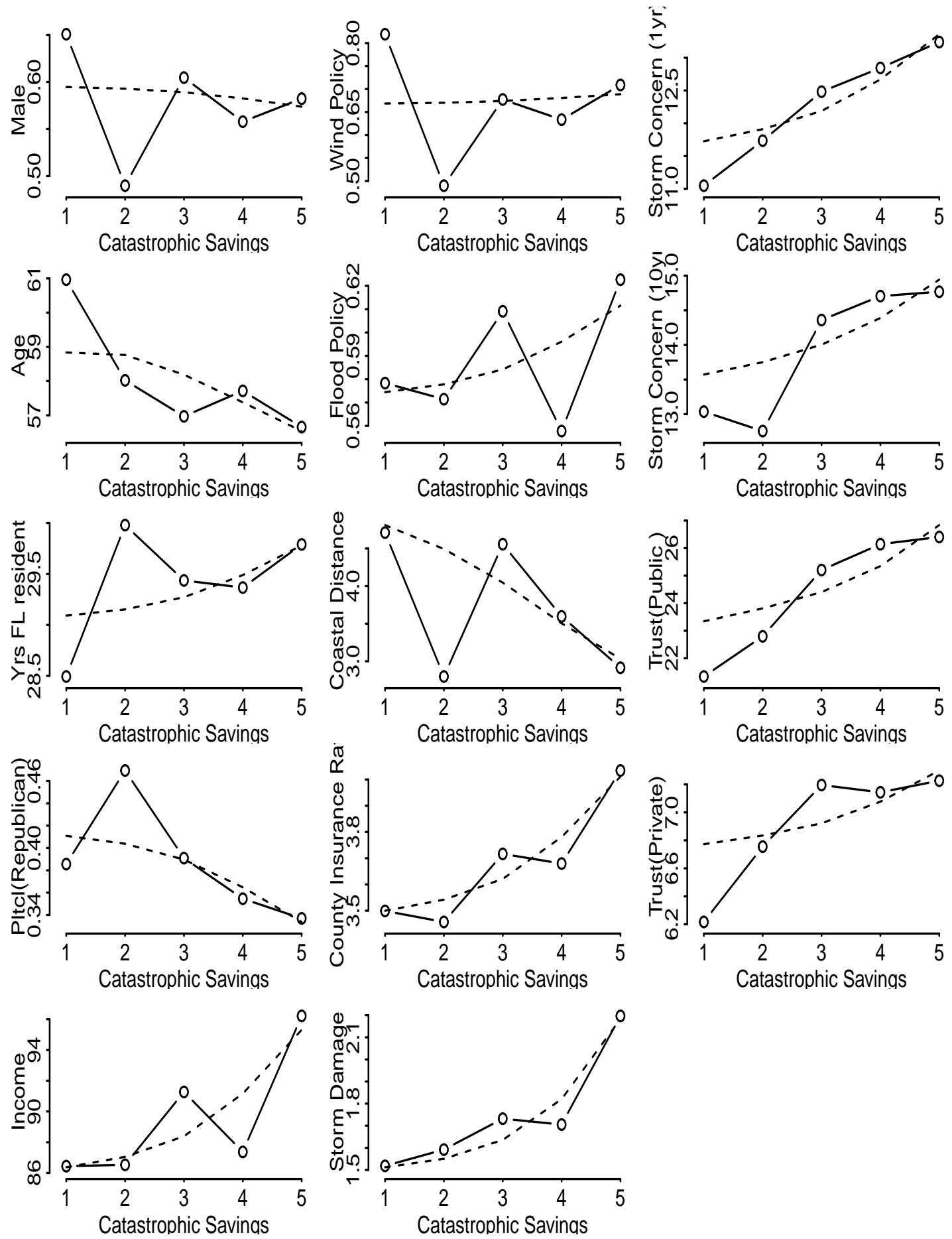
Figure A6: Proportional Odds Assumption: Binary model score residuals of individual covariates with levels of Surcharge
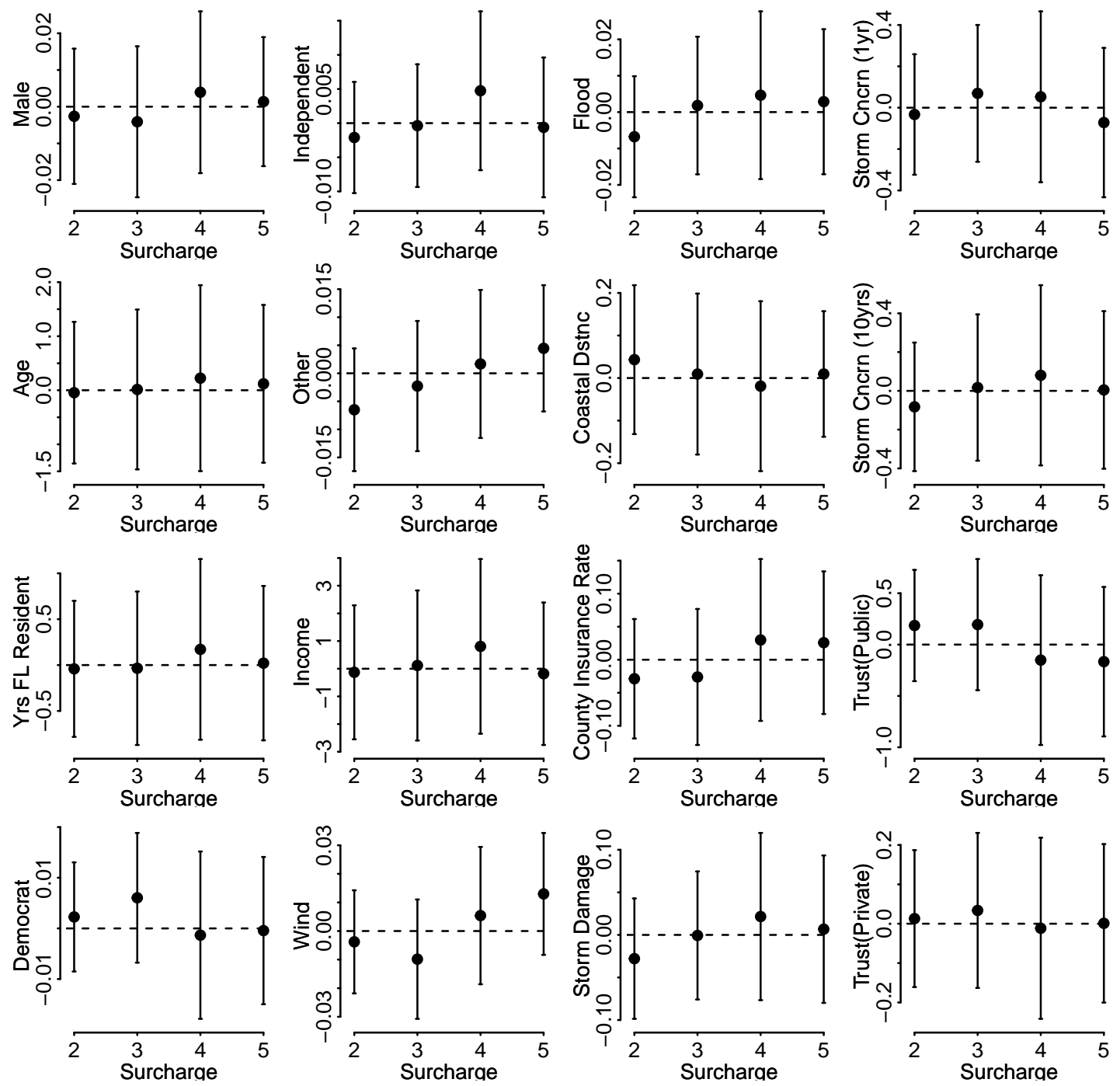
Figure A7: Proportional Odds Assumption: Binary model score residuals of individual covariates with levels of Flood(5yr)
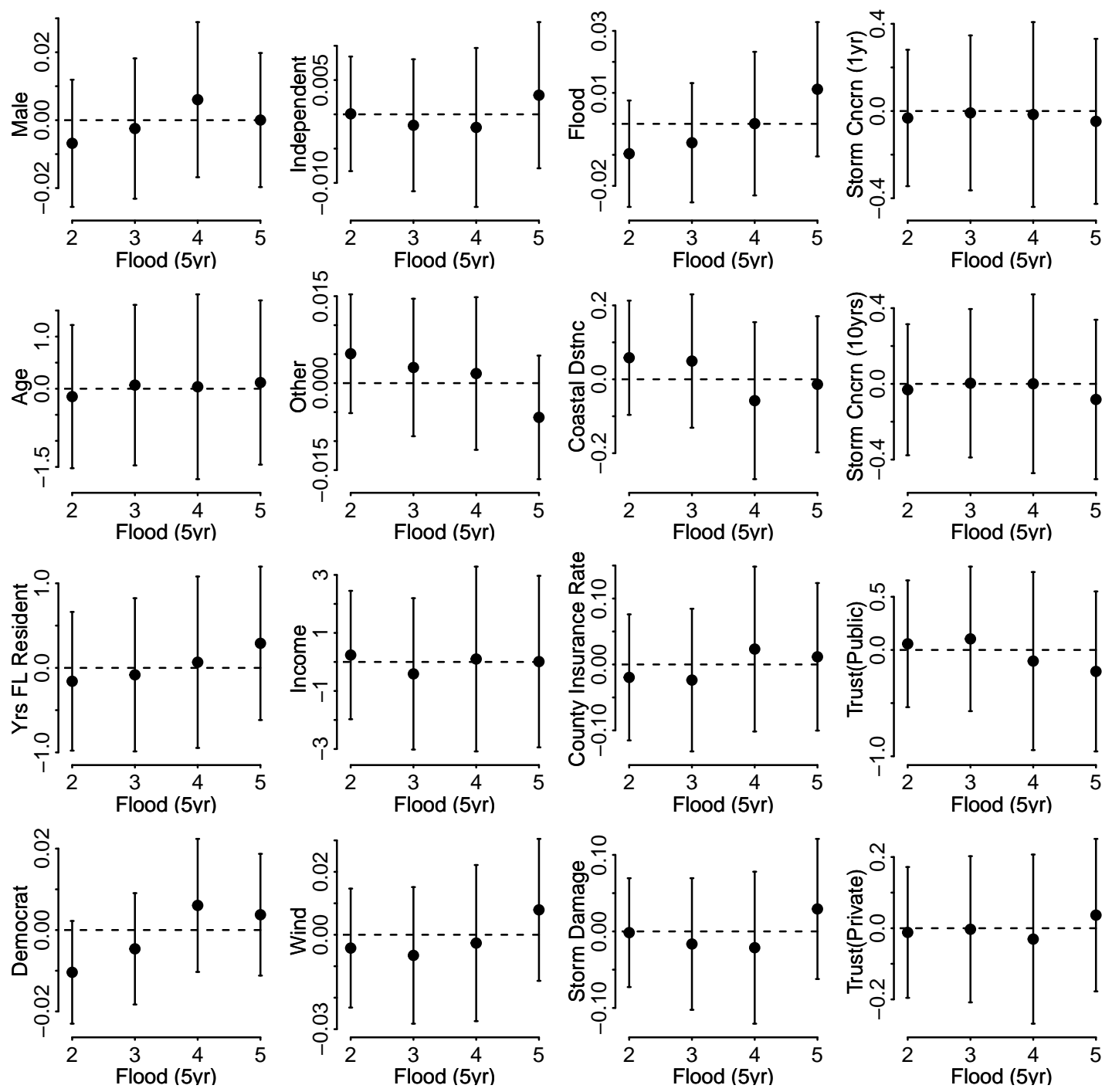
Figure A8: Proportional Odds Assumption: Binary model score residuals of individual covariates with levels of Flood(30yr)
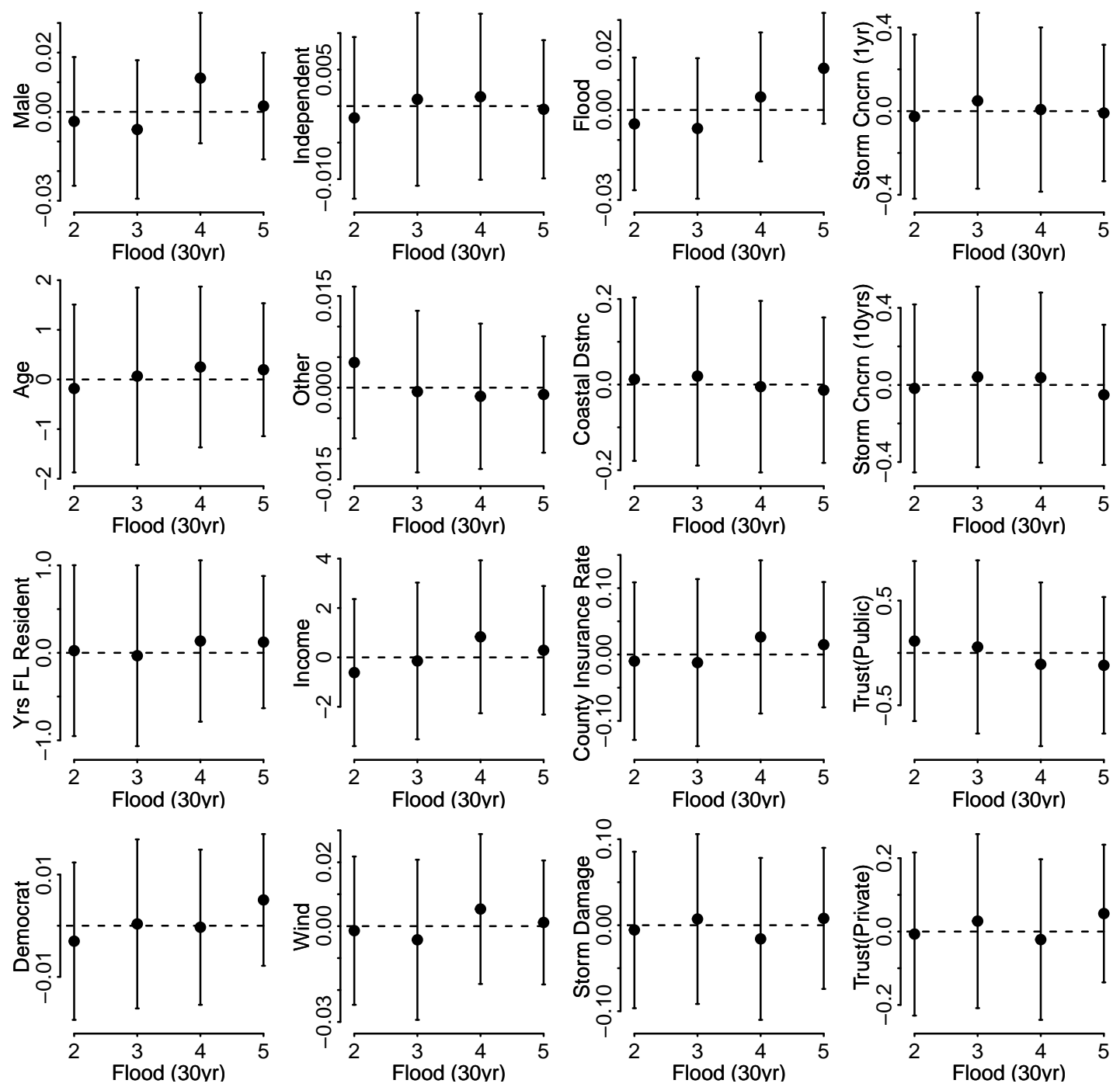
Figure A9: Proportional Odds Assumption: Binary model score residuals of individual covariates with levels of All Hazards
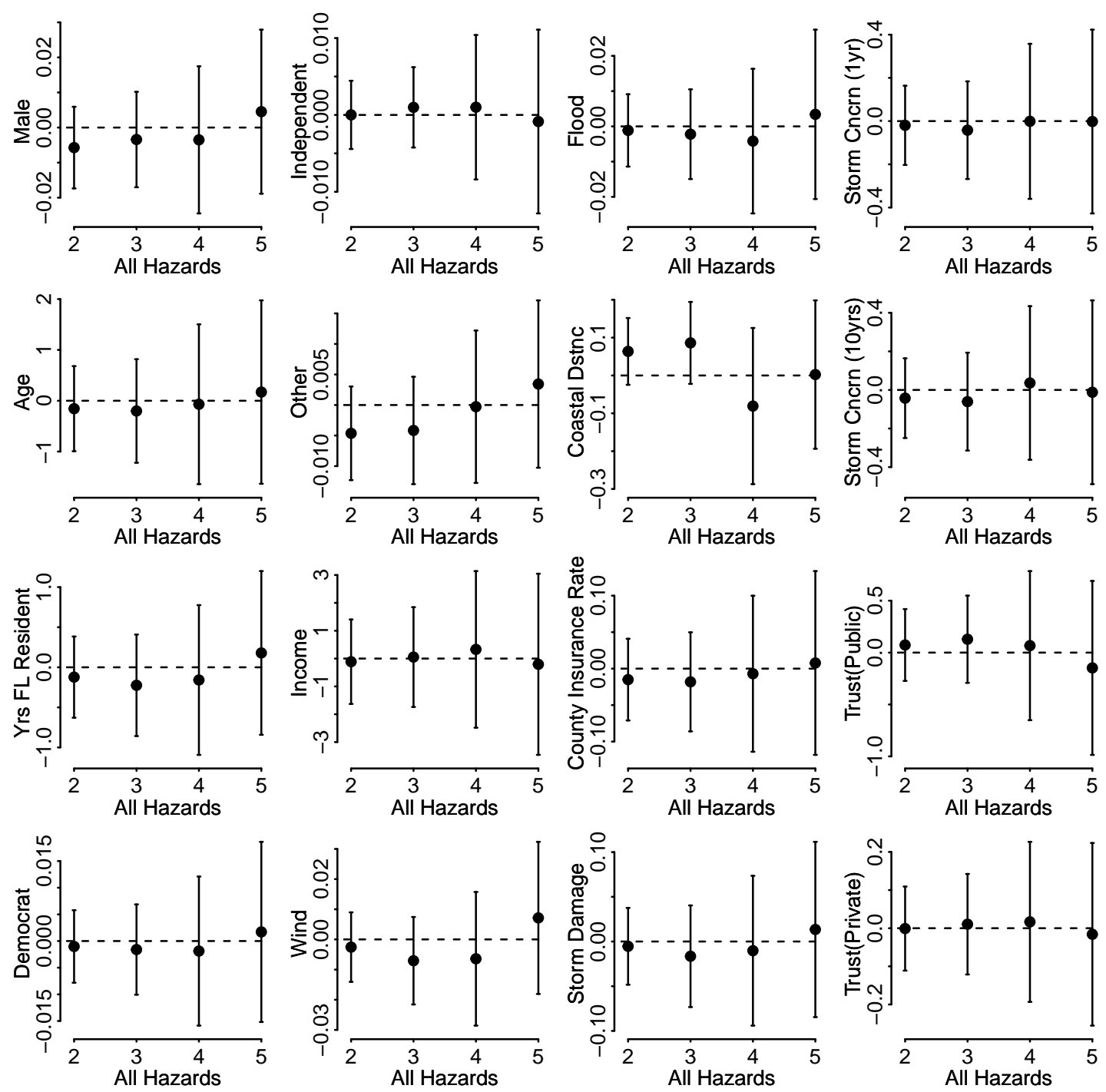
Figure A10: Proportional Odds Assumption: Binary model score residuals of individual covariates with levels of Catastrophic Savings
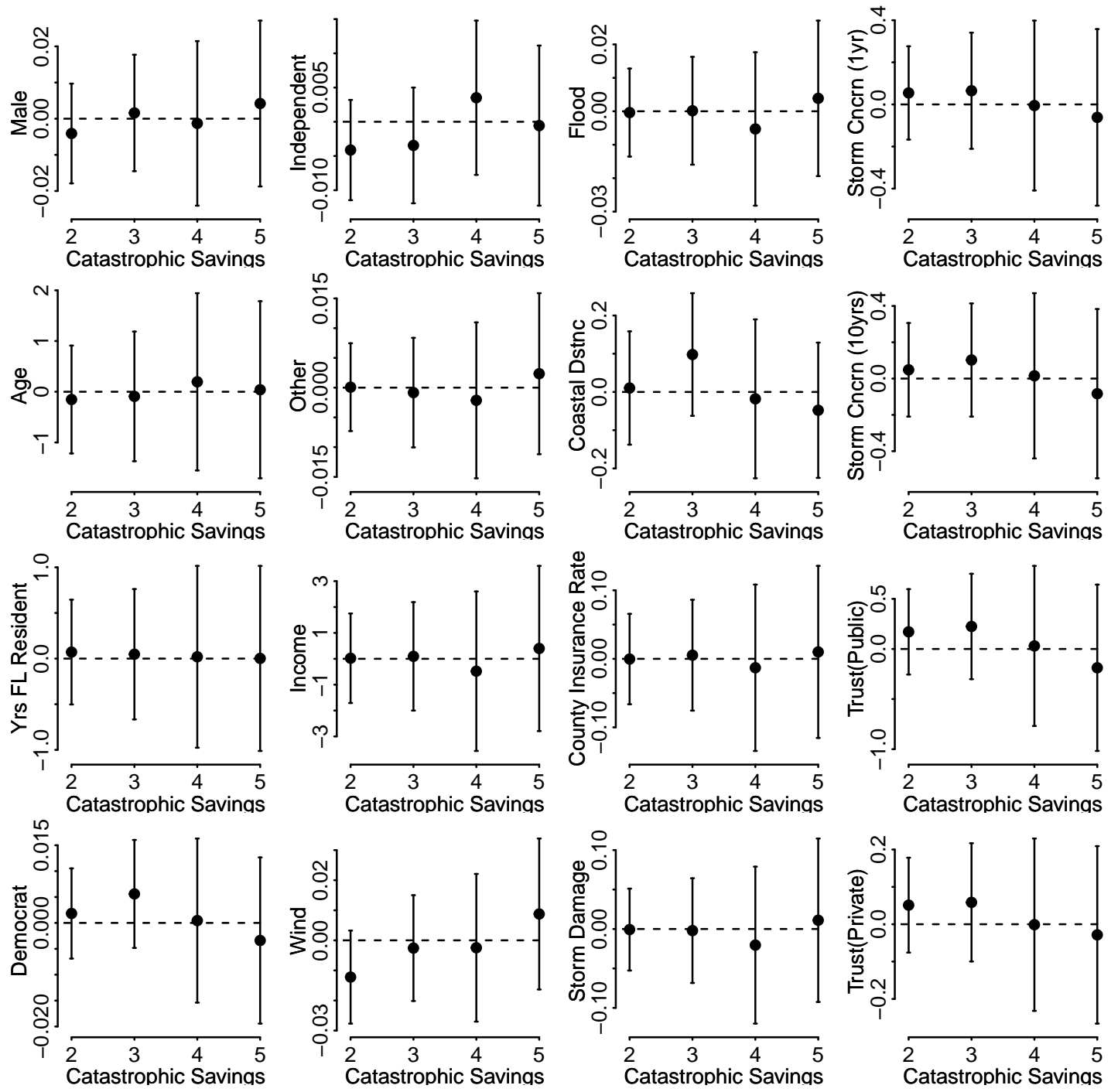